Supporting Information

\title{
Comparison of Mobile and Fixed-Site Black Carbon Measurements for High-Resolution Urban Pollution Mapping
}

Sarah E. Chambliss ${ }^{\mathrm{a}}$, Chelsea V. Preble ${ }^{\mathrm{b}, \mathrm{c}}$, Julien J. Caubel ${ }^{\mathrm{c}, \mathrm{d}}$, Troy Cados $^{\mathrm{b}, \mathrm{c}}$, Kyle P. Messier $^{\mathrm{a}, \mathrm{e}}$, Ramón A. Alvarez ${ }^{\mathrm{e}}$, Brian LaFranchi ${ }^{\mathrm{f}}$, Melissa Lunden ${ }^{\mathrm{f}}$, Julian D. Marshall ${ }^{\mathrm{g}}$, Adam A. Szpiro ${ }^{\mathrm{h}}$, Thomas W. Kirchstetter ${ }^{\mathrm{b}, \mathrm{c}}$, and Joshua S. Apte $\mathrm{a}^{\mathrm{a}, \mathrm{i}, *}$

${ }^{a}$ Department of Civil, Architectural and Environmental Engineering, University of Texas at Austin, Austin, Texas 78712, United States

${ }^{b}$ Department of Civil and Environmental Engineering, University of California, Berkeley, Berkeley, California, 94720, United States

${ }^{c}$ Energy Technologies Area, Lawrence Berkeley National Laboratory, Berkeley, California, 94720, United States

d Department of Mechanical Engineering, University of California, Berkeley, Berkeley, California, 94720, United States

e Environmental Defense Fund, Austin, Texas 78701, United States

${ }^{\mathrm{f}}$ Aclima, Inc., 10 Lombard Street, San Francisco, California 94111, United States

g Department of Civil and Environmental Engineering, University of Washington, Seattle, WA 98195, United States

${ }^{\mathrm{h}}$ Department of Biostatistics, University of Washington, Seattle, Washington 98195, United States

i School of Public Health, University of California, Berkeley, California 94720, United States

* Corresponding author. Email: apte@berkeley.edu

This PDF file includes 34 pages containing:

1. Methods

2. Results, Discussion, and Supplemental Analyses

3. Figures $\mathrm{S} 1$ to $\mathrm{S} 17$

4. Tables S1 to S12

5. SI References 


\section{S1. Materials and Methods}

\section{S1.1. Comparison Metrics}

We evaluate agreement among instruments (PAX-to-PAX, PAX-to-ABCD, and PAX-to-AE33) using $\mathrm{R}^{2}$ from least squares regression; we evaluate relative precision based on mean absolute error (MAE), root-mean-square error (RMSE), and normalized root-mean-square error (NRMSE); and evaluate bias based on mean bias error (MBE) and fitted linear equations. When comparing between $\mathrm{PAX}$ and $\mathrm{ABCD}$ measurements, either during controlled co-location (in the garage) or in-situ co-location, we follow the convention that $\mathrm{x}=$ measurements by mobile lab (PAX),

$\mathrm{y}=$ measurement by $\mathrm{ABCD}$, and $\bar{y}=$ mean value of $\mathrm{y}$.

We calculate root mean square error, RMSE, as

$$
\text { Eq. (S1) } \quad \mathrm{RMSE}=\sqrt{\frac{1}{N} \sum_{i=1}^{N}\left(y_{i}-x_{i}\right)^{2}}
$$

RMSE here and throughout is calculated from difference between $\mathrm{y}$ and $\mathrm{x}$ (measurements from mobile lab and $\mathrm{ABCD}$ ), not $\mathrm{y}$ and $\hat{\mathrm{y}}$ (measurement of mobile lab vs. prediction of $\mathrm{ABCD}$ based on mobile lab linear regression).

We calculate normalized root mean square error, NRMSE, as

$$
\text { Eq. (S2) NRMSE }=\frac{R M S E}{\bar{y}}
$$

We calculate mean bias error, MBE, as

$$
\text { Eq. (S3) } \quad \mathrm{MBE}=\frac{1}{N} \sum_{i=1}^{N}\left(y_{i}-x_{i}\right)
$$

We calculate mean absolute error, MAE, as

$$
\text { Eq. (S4) } \quad \mathrm{MAE}=\frac{1}{N} \sum_{i=1}^{N}\left|y_{i}-x_{i}\right|
$$




\section{S1.2. Calculation of effective limit of detection (LOD)}

Effective LOD is calculated from Eq. 1 and 2 based on time integration period $\mathrm{n}_{\mathrm{Hz}}$ : the total count of valid $1 \mathrm{~Hz}$ measurements at a given road segment over the duration of the driving campaign. Two additional maps show data processed with a $10 \mathrm{~s}$ and $20 \mathrm{~s}$ moving average, corresponding to an approximate spatial smoothing of $90 \mathrm{~m}$ and $190 \mathrm{~m}$ (average non-highway vehicle speed of $9.3 \mathrm{~m} / \mathrm{s})$. For these maps, an extended time integration period $\mathrm{n}_{\text {smoothed }}$ is calculated as the sum of $1 \mathrm{~Hz}$ measurements $\left(\mathrm{n}_{\mathrm{Hz}}\right)$ plus a number of measurements (depending on moving average period) made directly before and after each road segment visit,

Eq. (S5) $\mathrm{n}_{\text {smoothed }}=\mathrm{n}_{\mathrm{Hz}}+(\mathrm{S}-1) \mathrm{v} \quad$ where

$\mathrm{n}_{\mathrm{Hz}}$ is the count of valid $1 \mathrm{~Hz}$ measurements at a given road segment,

$\mathrm{S}$ is the smoothing period in seconds (10 or 20), and

$\mathrm{v}$ is the count of visits to the road segment. 


\section{S2. Results, Discussion, and Supplemental Analyses}

\section{S2.1 Analysis by land use category}

Within the $\mathrm{ABCD}$ network, localized land use strongly affects total $\mathrm{BC}$ concentrations as well as diurnal and weekly concentration patterns. ${ }^{1}$ We conducted a limited investigation of how the comparison of mobile and fixed-site monitoring may vary by land use type. The assignment of land use categories is based on West Oakland city planning data and described more fully by Caubel et al. ${ }^{1}$ Because the division of data among sites is not carefully balanced in this supplemental analysis (i.e., there are differing number of sites in each category and differing incidental mobile sampling intensity across categories), we are cautious in our interpretation of these results and seek to avoid drawing false inferences from patterns that may result from a reduced sample size. Bearing in mind this important caveat, we find some tentative evidence of differing spatial fidelity of mobile measurements and sampling requirements by land use category.

Figure S13 compares results of the core analysis at $30 \mathrm{~m}$ and $95 \mathrm{~m}$ for two categories typifying low-concentration and high-concentration areas: residential sites and sites along truck routes. Daytime $\mathrm{ABCD}$ medians (units: $\mu \mathrm{g} \mathrm{m}^{-3}$ ) ranged from 0.32 to 0.57 at residential sites $($ mean $=0.44)$, and 0.45 to 1.31 at truck route sites $($ mean $=0.66)$. This figure shows that for a 30 $\mathrm{m}$ buffer, instrument error limits the ability of mobile monitoring to resolve concentration differences among sites for both land use categories. Increasing the buffer radius to $95 \mathrm{~m}$ results in substantial decrease in normalized mean absolute error for both categories, dropping from $45 \%$ to $24 \%$ in residential areas and from $25 \%$ to $9 \%$ near truck routes. However, correlation only increased significantly for truck route sites $\left(R^{2}=0.67\right)$. This finding suggests that the increase in per-spatial-unit sampling time reduces uncertainty in mobile-monitoring-based 
estimates of long-term concentrations in many land-use areas, but may only improve the representation of spatial patterns in areas with a higher range of concentrations.

In addition, Figure S14 presents correlation from the temporal representativeness comparison as a function of the total number of site visits, each accounting for at least 1 minute of $\mathrm{ABCD}$ measurements. We find that for the same number of visits, the temporal subset resolves spatial patterns significantly better for truck route sites than residential sites. This result suggests that fewer visits may be necessary to compensate for temporal sparsity in areas with a higher signalto-noise ratio. A more carefully balanced comparison among land use types may reveal further insight and is a useful direction for future research.

\section{S2.2. Instrument and temporal sampling bias ratios}

In-situ PAX-to-ABCD bias and temporal bias were broadly consistent across sites but did show some variation. Figure 10 represents bias using the ratios of five sets of site medians: A, mobile monitoring daytime medians; $\mathrm{B}$, medians of fixed-site temporal subset during daytime mobile monitoring; C, fixed-site 100-day daytime medians; D, fixed-site 100-day overall medians. Here, we present ratios for all six possible combinations of these variables; the most important three are $\mathrm{A} / \mathrm{B}, \mathrm{B} / \mathrm{C}$, and $\mathrm{C} / \mathrm{D}$. The first key ratio, $\mathrm{A} / \mathrm{B}$, primarily reflects the in-situ PAX-to-ABCD bias, but is also influenced by spatial misalignment between the vehicle and the fixed site, aligned with comparison (ii). At the majority of sites, represented by the interquartile range, mobile measurements were lower than $\mathrm{ABCD}$ measurements, between $64 \%$ to $84 \%$ of $\mathrm{ABCD}$ concentrations. The second key ratio, $\mathrm{B} / \mathrm{C}$, represents the same data as in the temporal representativeness comparison (iii), and reflects the difference in sampling conditions during mobile monitoring at a site compared to overall daytime conditions. The majority of sites show a $\mathrm{B} / \mathrm{C}$ greater than 1 , with an interquartile range of 1.05 to 1.25 ; mobile sampling occurred during 
conditions typically $5 \%$ to $25 \%$ more polluted than overall daytime conditions. The third key ratio, C/D, represents the daytime sampling bias. Nearly all sites show higher average concentrations during the day than at night, resulting in daytime-to-overall ratios $>1$. The range in daytime bias among sites is relatively small, with the majority of sites falling in between ratios of 1.10 and 1.19 .

\section{S2.3. Sensitivity to long-range transport events}

Episodes of elevated background concentration due to long-range transport (LRT) of BC have the potential to impact correlation strength, by reducing variation among sites, and to impact temporal bias. To investigate the influence of elevated LRT events, we perform a sensitivity analysis integrating data from three upwind fixed-site ABCD sensors located along the shore of the San Francisco Bay '(location ID 50, 86, and 97) that indicate regional concentrations (see Caubel et al. ${ }^{1}$ ). Based on measurements from these sites, we find that longrange transport typically accounts for $50 \%$ of urban daytime concentrations $\left(\sim 0.3 \mu \mathrm{g} \mathrm{m}^{-3}\right)$. We identified four periods (June 18, July 7-8, July 16, and August 3-4) during which daily concentrations at upwind monitors consistently exceeded $0.75 \mu \mathrm{g} \mathrm{m}-3$, corresponding to the $90^{\text {th }}$ percentile of hourly daytime concentrations at those upwind sites. A repetition of our core analysis excluding measurements from these periods showed no meaningful difference in the core conclusions presented in this paper (Table S7).

\section{S2.4. In-motion co-location vs. short-term stationary co-location}

The two fixed sites with reference-grade BC instruments (Aethalometer model AE33) were located within the center of the domain and thus were among the most-visited sites ( $>150$ visits, $>95^{\text {th }}$ percentile). Comparisons of contemporaneous mobile and fixed-site measurements during in-motion visits (median duration $=28 \mathrm{~s}$ ) show poor correlation for $\mathrm{ABCD}$ instruments at 
both sites (visit means of $0.5 \mathrm{~Hz}$ measurements, $\mathrm{R}^{2}=0.04$ and 0.08 ) and for the AE33 instrument at site 3 (nearest 1 min mean to visit time, $\mathrm{R}^{2}=0.03$ ), with better correlation at site 4 driven by one outlier event (Table S7 and S8, Figures S12 and S13). Co-located AE33 and ABCD instruments are not themselves strongly correlated at that time resolution and for that temporal subsample $\left(\mathrm{R}^{2}=0.24\right.$, Table S9 and Figure S14).

Correlation of visit means improves significantly when site visits are lengthened from $\sim 20 \mathrm{~s}$ in-motion to $\sim 7$ minutes parked within $80 \mathrm{~m}$ of the site (median visit length $=7.3$ minutes, total time $=222 \mathrm{~min})$. Mobile lab measurements show an $\mathrm{R}^{2}$ of 0.65 with $\mathrm{ABCD}$ instruments and an $\mathrm{R}^{2}$ of 0.67 with AE33 instruments (Tables S10 and S11, Figures S15 and S16). Normalized root-mean-square error between mobile measurements and ABCD measurements dropped from $138 \%$ during in-motion visits to $45 \%$ during short-term co-locations; comparisons with AE33 measurements showed a comparable drop from $93 \%$ to $40 \%$ NRMSE. For both the ABCD and AE33, the MAE of measurements collected during these long stationary samples is equal to $\sim 0.2$ $\mu \mathrm{g} \mathrm{m} \mathrm{m}^{-3}$, higher than that shown in Figure 3, as mobile measurements are consistently biased low relative to relative both the ABCD and AE33 (the ABCD and AE33 agree closely with one another, $\mathrm{R}^{2}=0.94$ and $\mathrm{MAE}=0.1 \mu \mathrm{g} \mathrm{m}^{-3}$ for this same data subsample, Table $\left.\mathrm{S} 12\right)$. This stationary subsample analysis is shown in Figures S12 to S13, and Tables S9 to S12.

In this context, with high instrument noise relative to ambient concentrations, rapid-pass mobile measurements are poorly suited for real-time mapping of fine scale BC spatial patterns, although this approach may perform better for settings and pollutants where concentrations are high relative to the (method/instrumental) detection limit. In cases where spatially distributed, real-time estimates of concentrations are desired, instrument precision limitations may be overcome by extending sampling time at locations of interest. 


\section{S3. Supporting Information Figures}

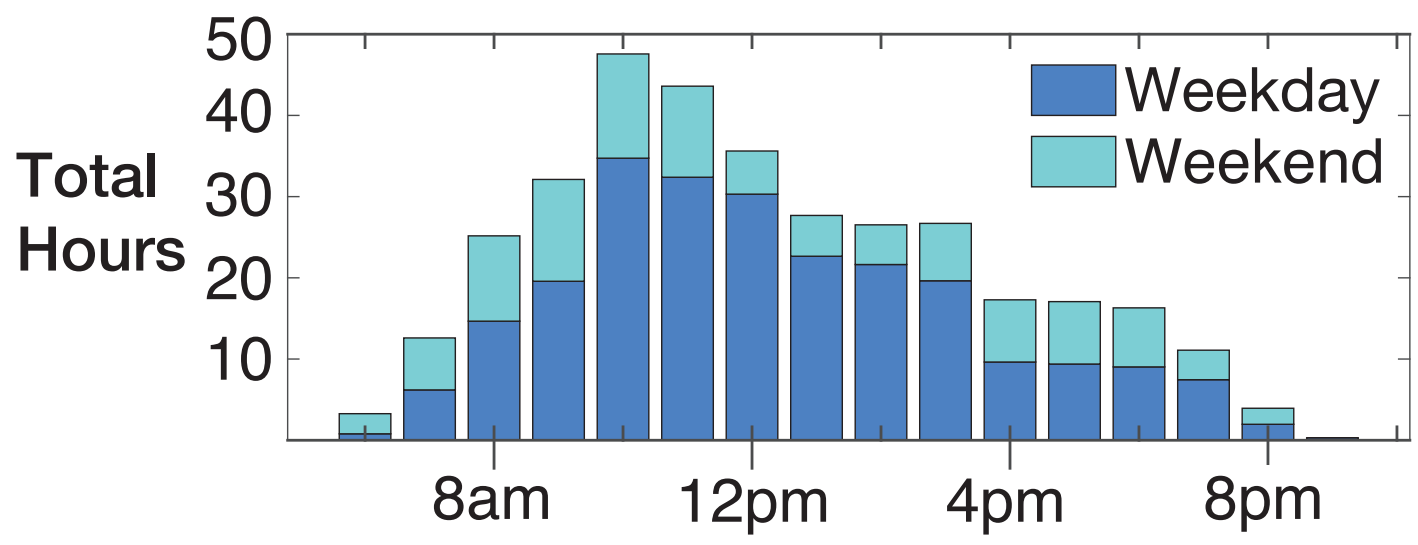

Figure S1. Total hours of mobile monitoring within the study domain by hour of the day. Colors indicate weekday or weekend driving. Most driving within the domain was conducted on weekdays between the hours of 9am and $5 \mathrm{pm}$.

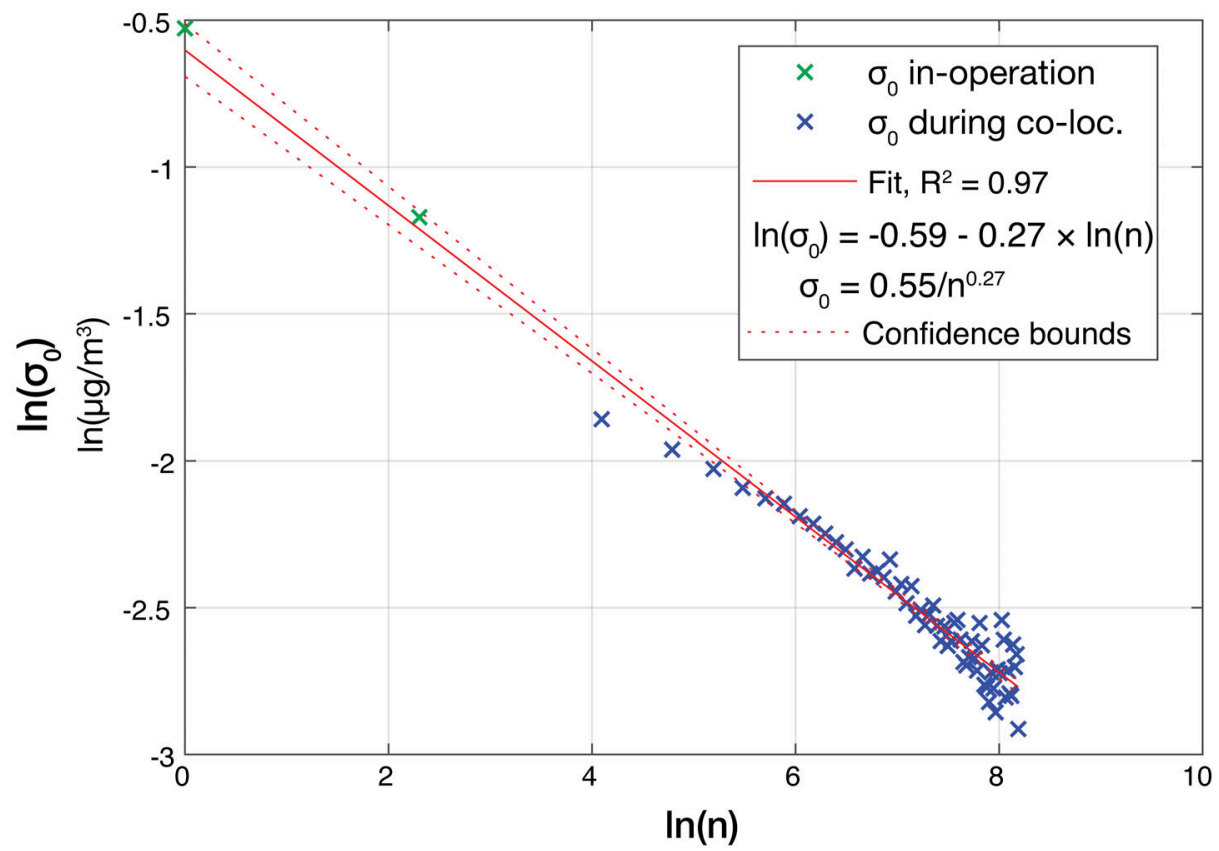

Figure S2. The linear fit of the log-transformed $t$ instrument error, $\sigma_{0}$, as a function of the logtransformed time-integration period $\mathrm{n}$. Green points indicate instrument error values derived from in-operation noise measurements, and blue points indicate instrument error values derived from garage co-location data using the Grubbs 3-instrument technique (see Table 2). 
a.
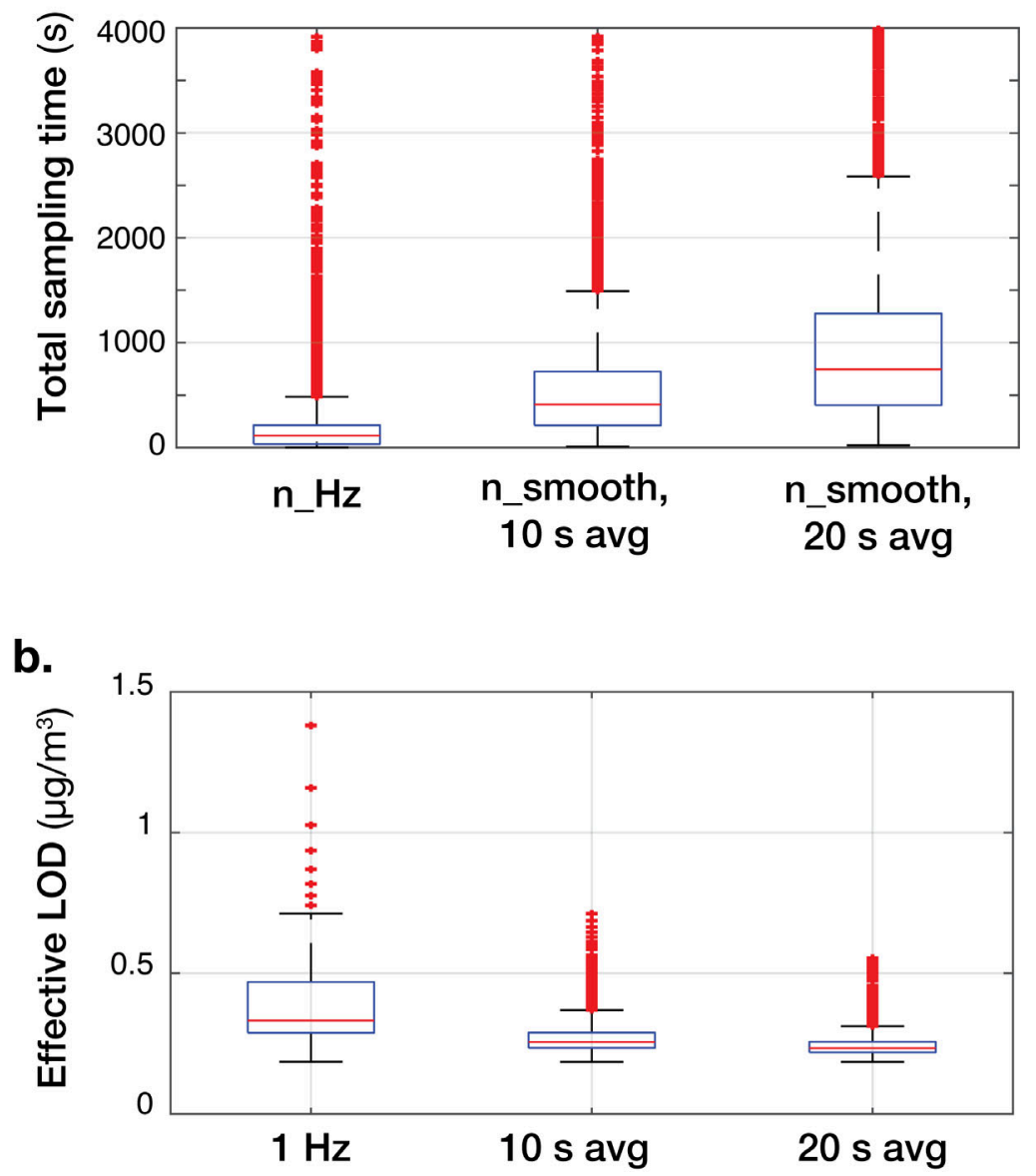

Figure S3. Box plots representing the distribution of values across all $30 \mathrm{~m}$ road segments within the sampling domain of: (a) the time integration period, either $\mathrm{n}_{\mathrm{HZ}}$, the total count of valid $1 \mathrm{~Hz}$

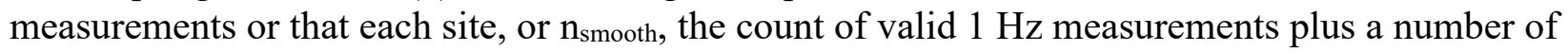
measurements depending on moving average period; and (b) the effective LOD calculated as a function of total sampling time (see Eq. 1). Distributions are shown for $1 \mathrm{~Hz}$ data, and temporally smoothed data calculated using a moving average of 10 or $20 \mathrm{~s}$. Longer averaging periods result in greater total sampling time and thus lower effective LOD values. 
a.

$1 \mathrm{~Hz}$ (no smoothing)

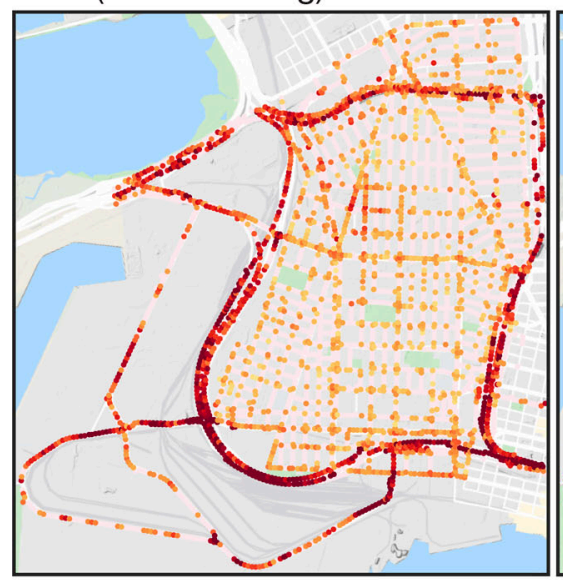

b.

10 s moving average

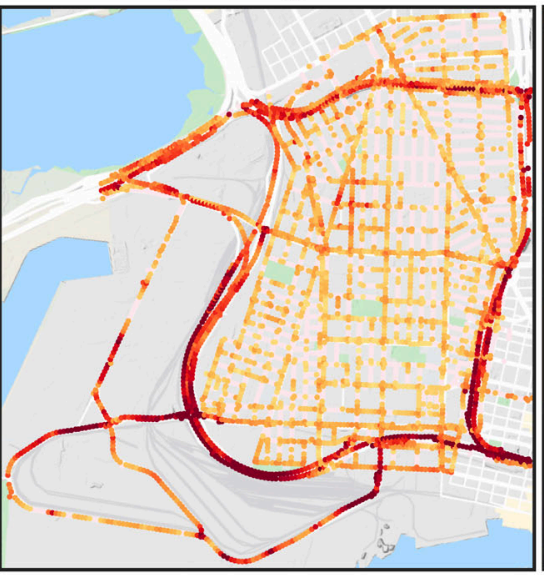

C.

20 s moving average

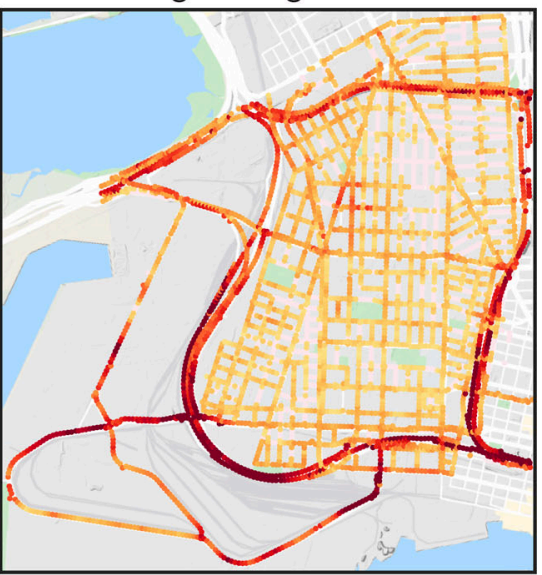

Median BC Concentration 0

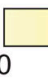

0.2
0.4

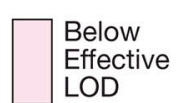

0.6

$\mu \mathrm{g} / \mathrm{m}^{3}$
0.8

0.8

Figure S4. Median black carbon concentration of all mobile monitoring data collected during the campaign. Circles represent median daytime (9am $-5 \mathrm{pm}) \mathrm{ABCD}$ measurements at fixed sites and on-road coloration shows mobile monitoring data at three time resolutions $(1 \mathrm{~Hz}, 10$ moving average, $20 \mathrm{~s}$ moving average), represented as the median of drive-pass means calculated for 30 $\mathrm{m}$ road segments. Light pink coloration indicates segments that are below the effective LOD. Map data (C) 2020 Google. 
Figures S5 a-d. Street-view scenes from markers on Figure 1, imagery (C) 2020 Google Maps Street View.

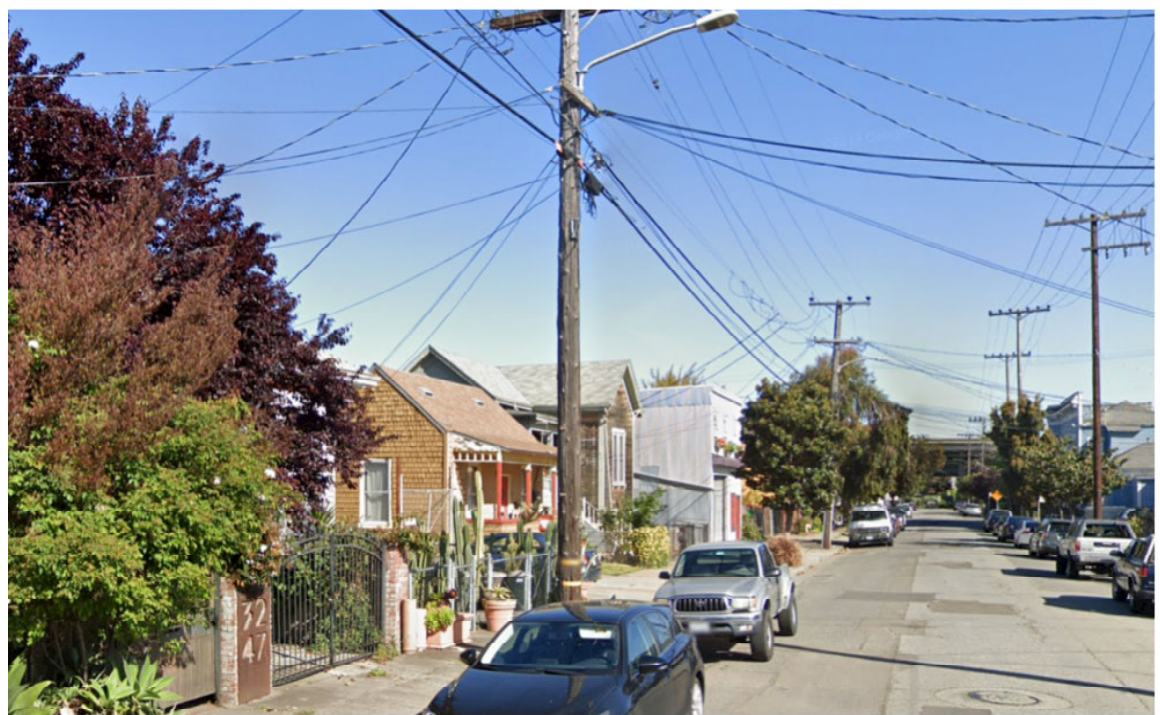

Figure S5a. Roads within a residential neighborhood several blocks from an elevated section of Interstate 580 , visible in the background. $37^{\circ} 49^{\prime} 27^{\prime \prime} \mathrm{N}, 122^{\circ} 17^{\prime} 13^{\prime \prime} \mathrm{W}$.

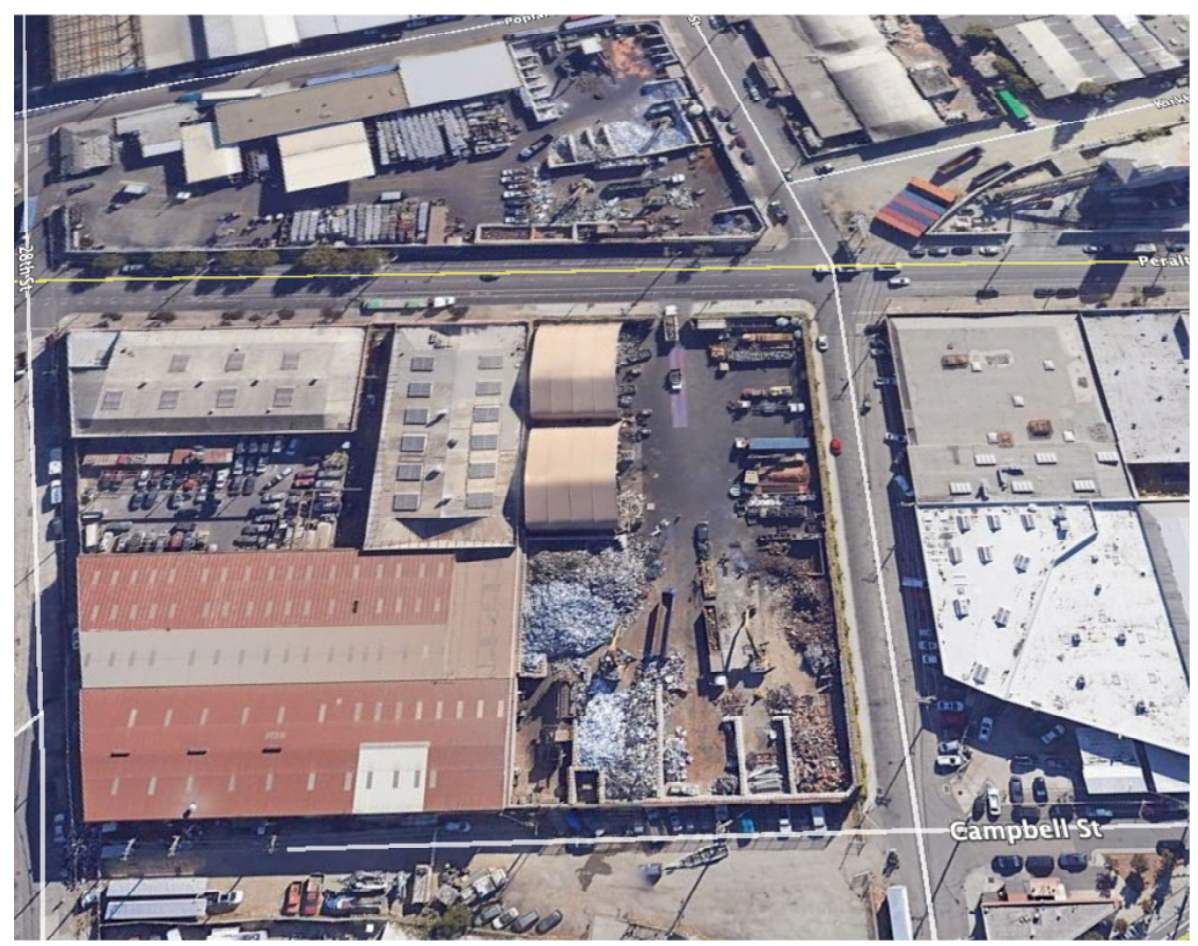

Figure S5b. Area of industrial activity including a cement plant and metals recycling business. $37^{\circ} 49^{\prime} 15^{\prime \prime} \mathrm{N}, 122^{\circ} 17^{\prime} 11^{\prime \prime} \mathrm{W}$. 


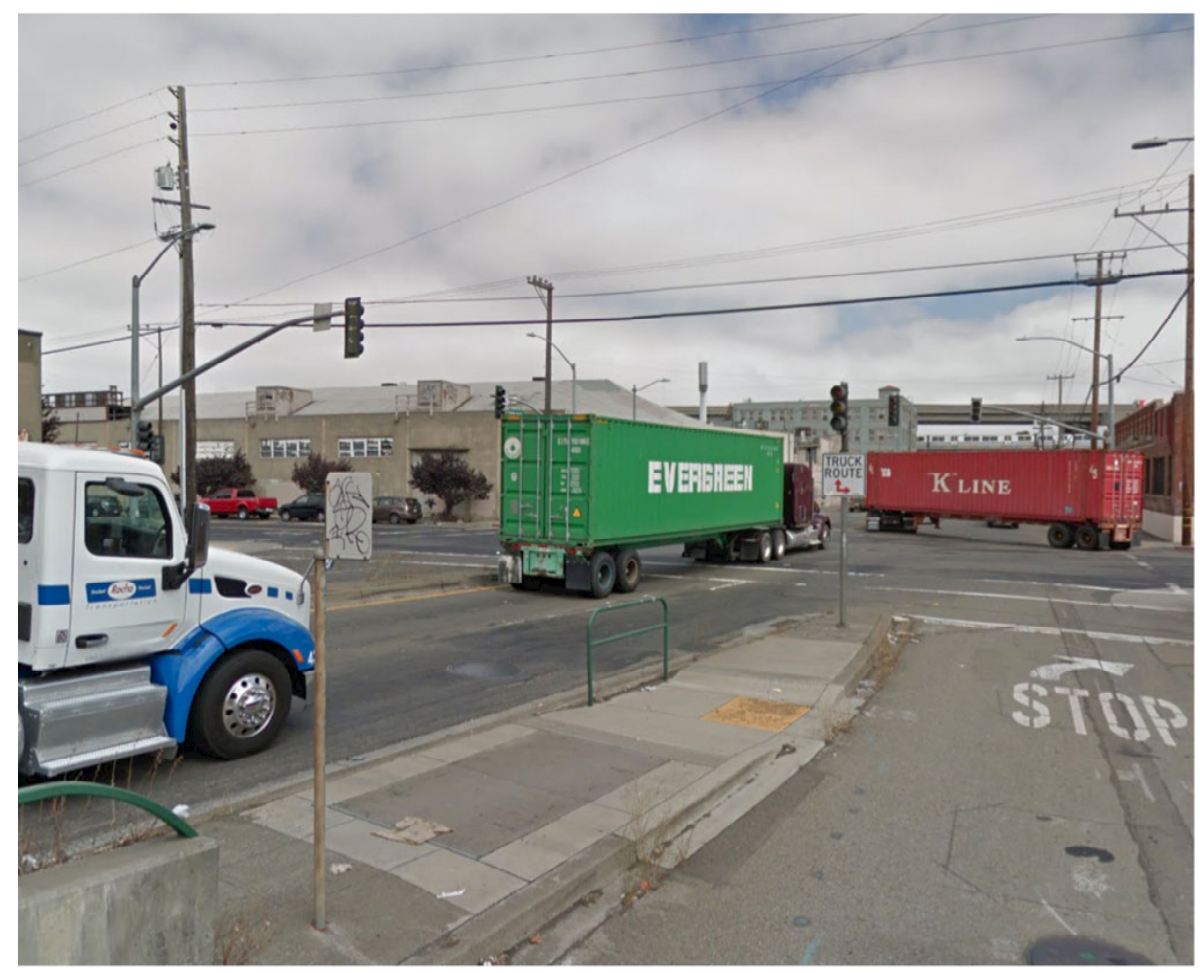

Figure S5c. Major 4-way stop near an overpass of Interstate 880 that acts as a major funnel for truck traffic to the Port of Oakland. $37^{\circ} 48^{\prime} 03^{\prime \prime} \mathrm{N}, 122^{\circ} 17^{\prime} 20^{\prime \prime} \mathrm{W}$.

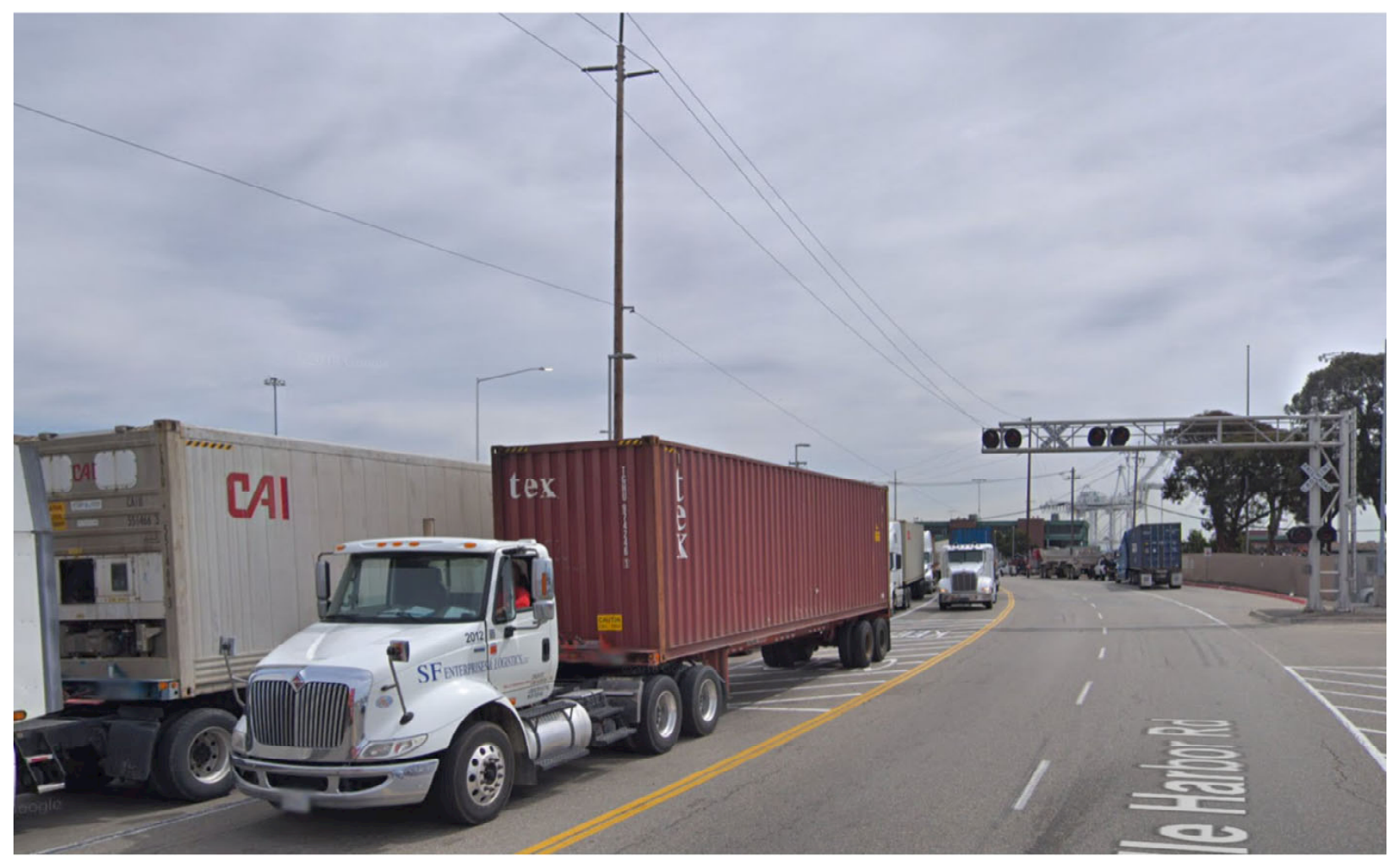

Figure S5d. Heavy-duty truck traffic near a railway crossing south of an entrance to the Port of Oakland. $37^{\circ} 47^{\prime} 52^{\prime \prime} \mathrm{N}, 122^{\circ} 18^{\prime} 15^{\prime \prime} \mathrm{W}$. 

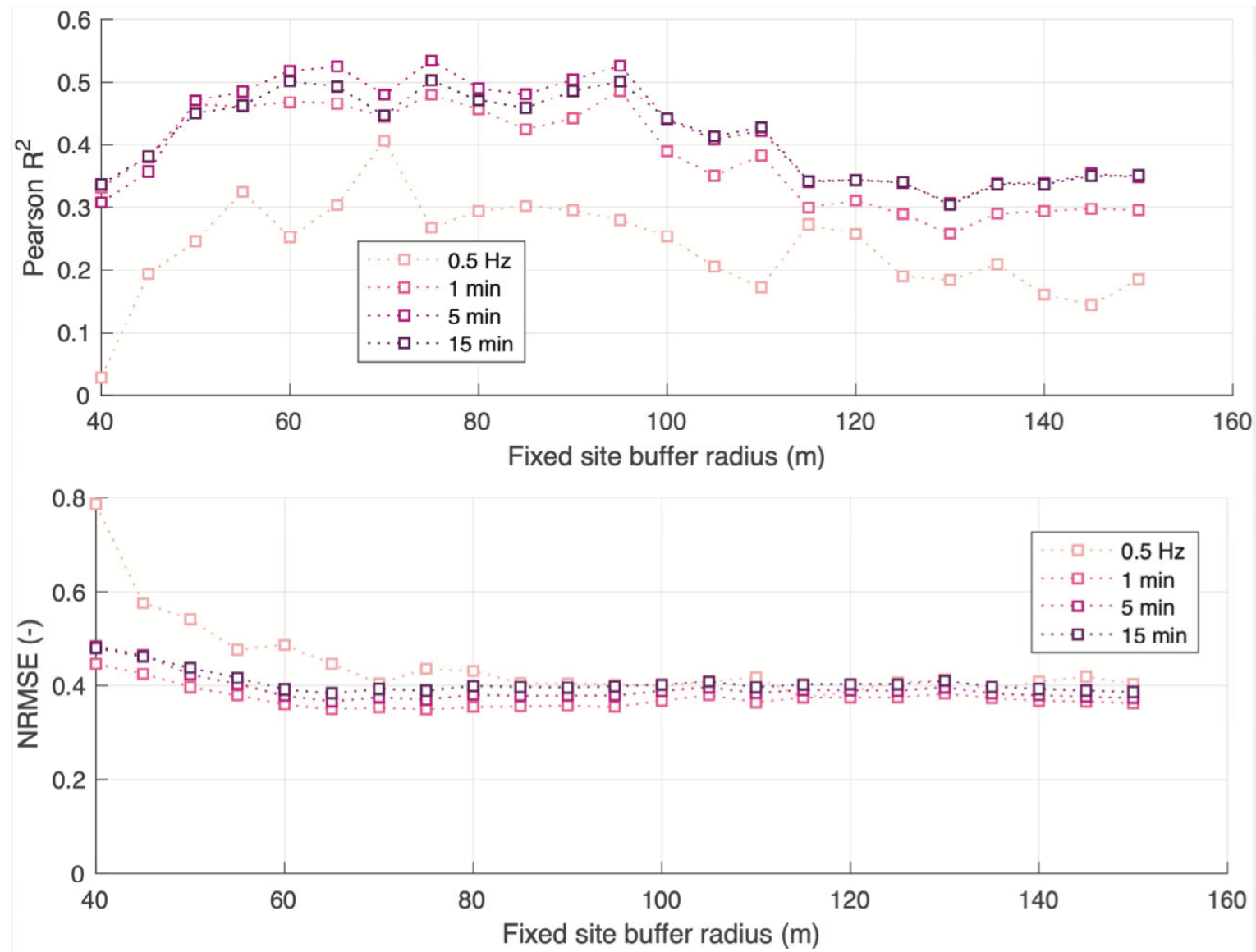

Figure S6. Results for contemporaneous subsample comparison using ABCD data at four time resolutions. 
a. Core Analysis (i)

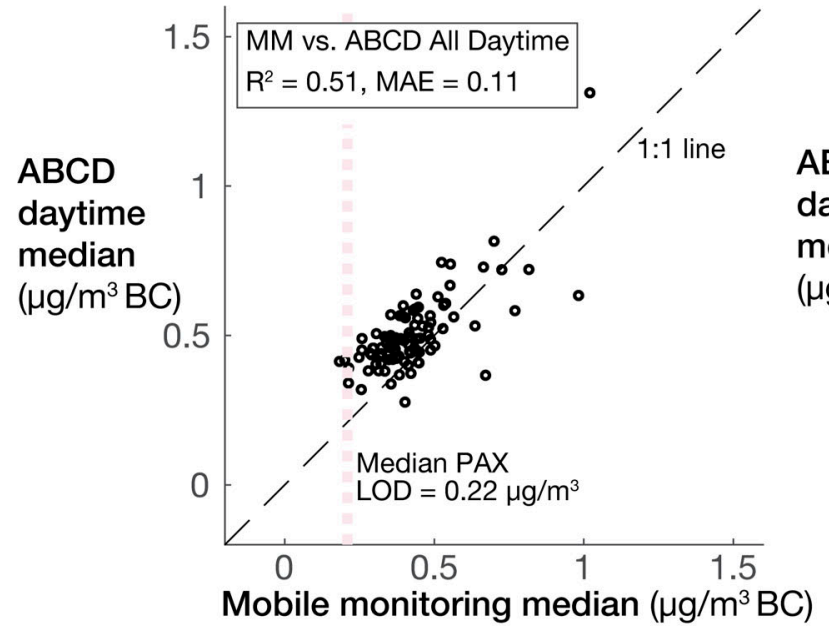

b. Contemporaneous Subsample (ii)

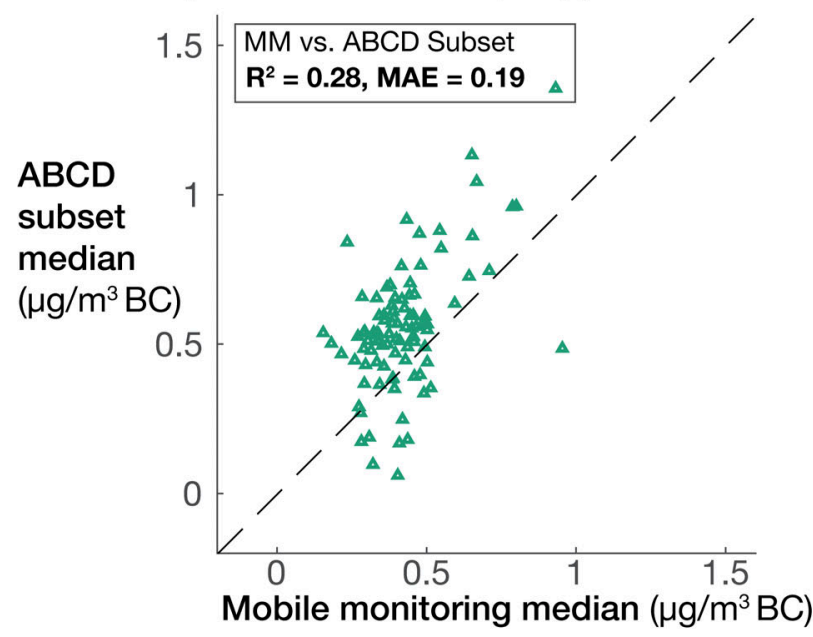

\section{c. Temporal Representativeness (iii)}

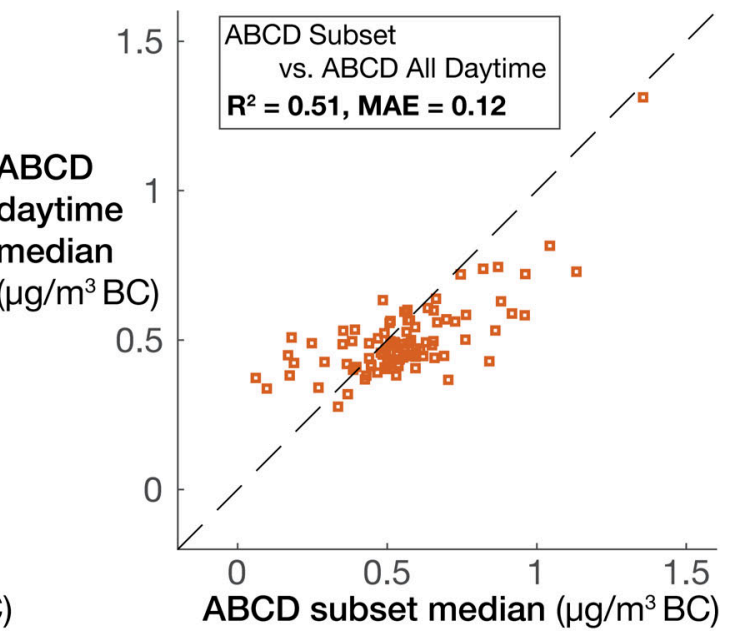

Total MM sampling time: $55.6 \mathrm{hr}$ Median visit count per site: 73 Median visit length: $17 \mathrm{~s}$ Median time per site: $29.3 \mathrm{~min}$ Median PAX precision: $0.15 \mu \mathrm{g} / \mathrm{m}^{3}$

Figure S7. As in Figure 3, this figure shows pairwise correlation between median BC concentrations measured by three distinct datasets: mobile monitoring visits (MM), ABCD measurements made during all daytime hours throughout the campaign (ABCD All Daytime), and the temporal subset of ABCD measurements made during mobile monitoring visits (ABCD subset) at a fixed-site radius of $95 \mathrm{~m}$. This version uses $0.5 \mathrm{~Hz} A B C D$ data for the contemporaneous subsample comparison (ii) and temporal representativeness comparison (iii). Data for the core analysis remain the same. The increased ABCD instrument noise at $0.5 \mathrm{~Hz}$, corresponding to an LOD of comparable magnitude to that of the PAX, results in lower correlation coefficients in comparison (ii), dropping to $\mathrm{R}^{2}=0.28$ from 0.49 , and comparison (iii), dropping to $\mathrm{R}^{2}=0.51$ from 0.74 . Mean absolute error increases by $0.02 \mu \mathrm{g} \mathrm{m}^{-3}$ in both comparison (ii) and (iii). 


\section{a. Core Analysis (i)}

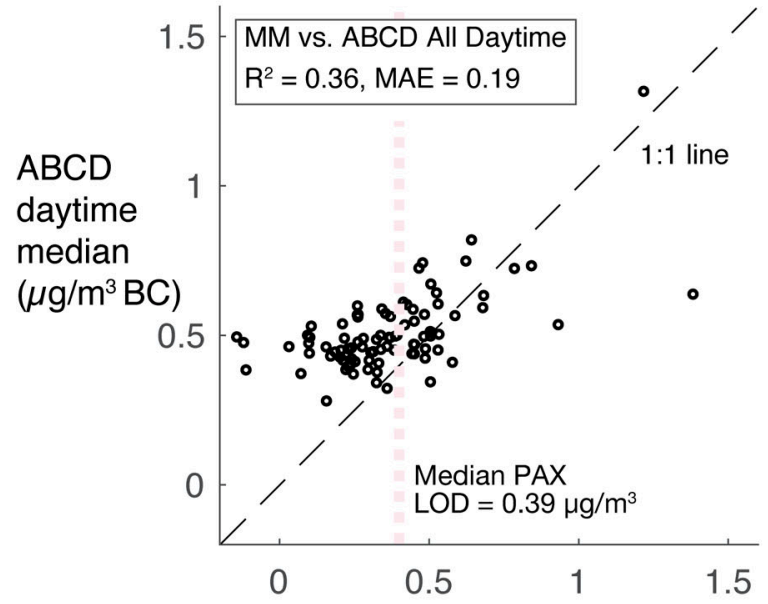

Mobile monitoring median $\left(\mu \mathrm{g} / \mathrm{m}^{3} \mathrm{BC}\right)$

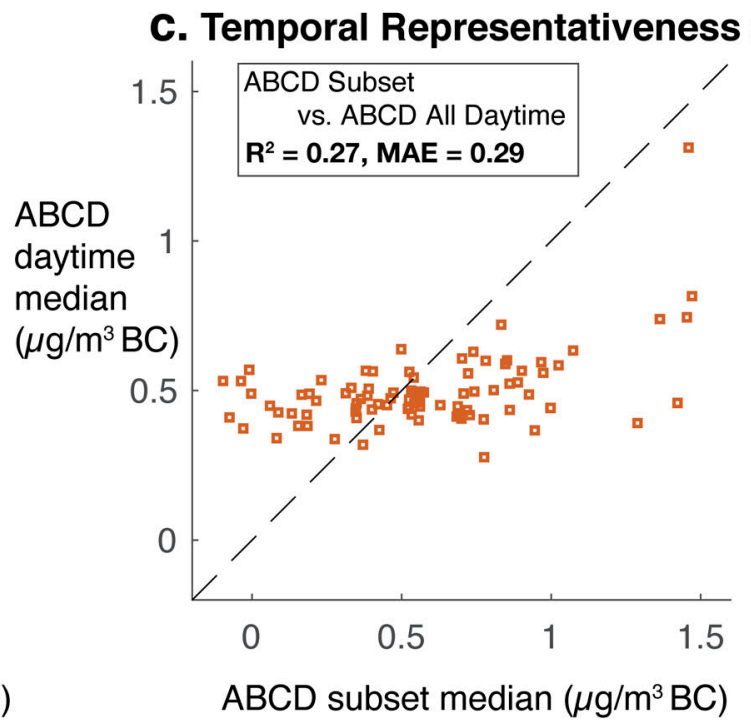

\section{b. Contemporaneous (ii)}

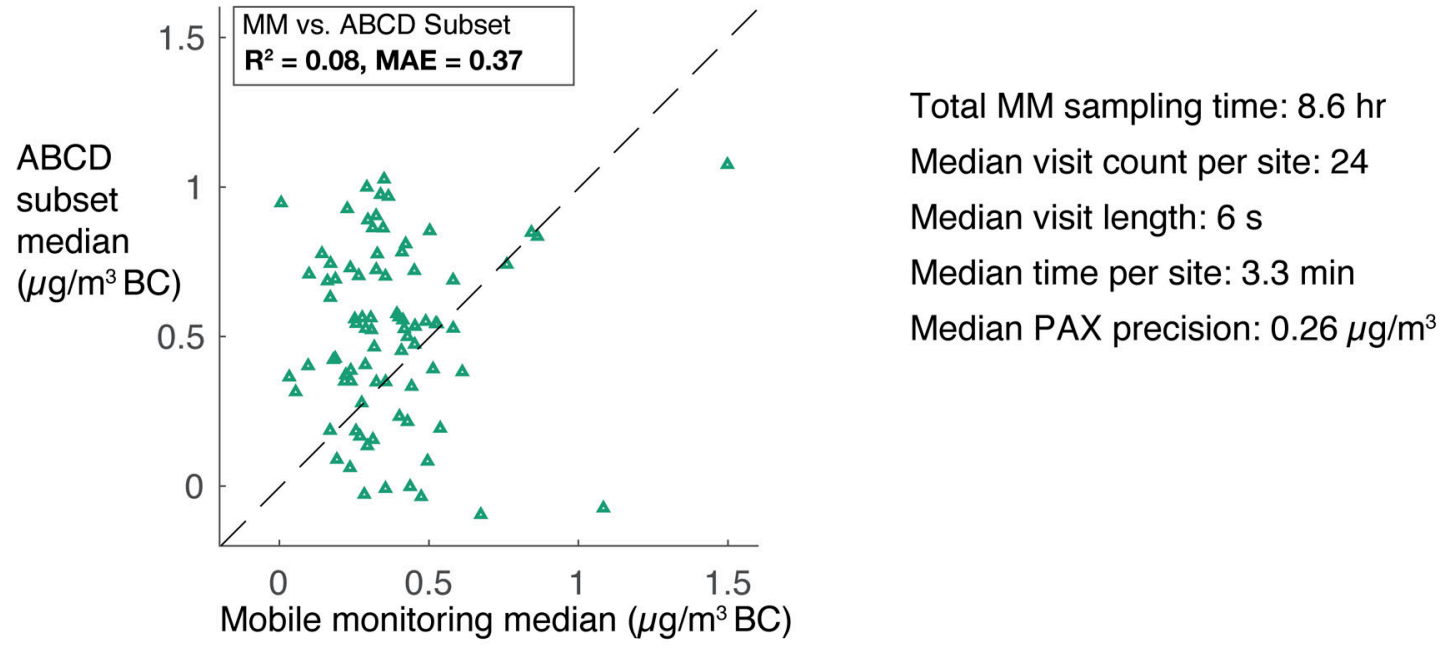

Figure S8. As in Figure S9, this figure shows pairwise correlation between median BC concentrations measured by three distinct datasets: mobile monitoring visits (MM), ABCD measurements made during all daytime hours throughout the campaign (ABCD All Daytime), and the temporal subset of $\mathrm{ABCD}$ measurements made during mobile monitoring visits (ABCD subset) at a fixed-site radius of $30 \mathrm{~m}$. This version uses $0.5 \mathrm{~Hz} A B C D$ data for the contemporaneous subsample comparison (ii) and temporal representativeness comparison (iii). Data for the core analysis remain the same. The increased ABCD instrument noise at $0.5 \mathrm{~Hz}$, corresponding to an LOD of comparable magnitude to that of the PAX, results in lower correlation coefficients in comparison (ii), dropping to $\mathrm{R}^{2}=0.08$ from 0.28 , and comparison (iii), dropping to $\mathrm{R}^{2}=0.27$ from 0.68 . Mean absolute error increases by $0.12 \mu \mathrm{g} \mathrm{m}^{-3}$ and $0.19 \mu \mathrm{g} \mathrm{m}^{-3}$ in comparisons (ii) and (iii), respectively. 
a. Core Analysis (i)

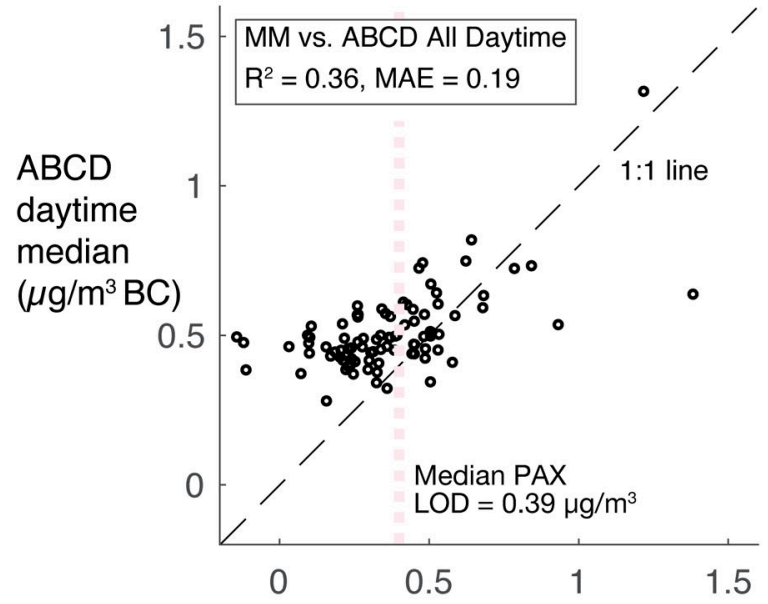

Mobile monitoring median $\left(\mu \mathrm{g} / \mathrm{m}^{3} \mathrm{BC}\right)$

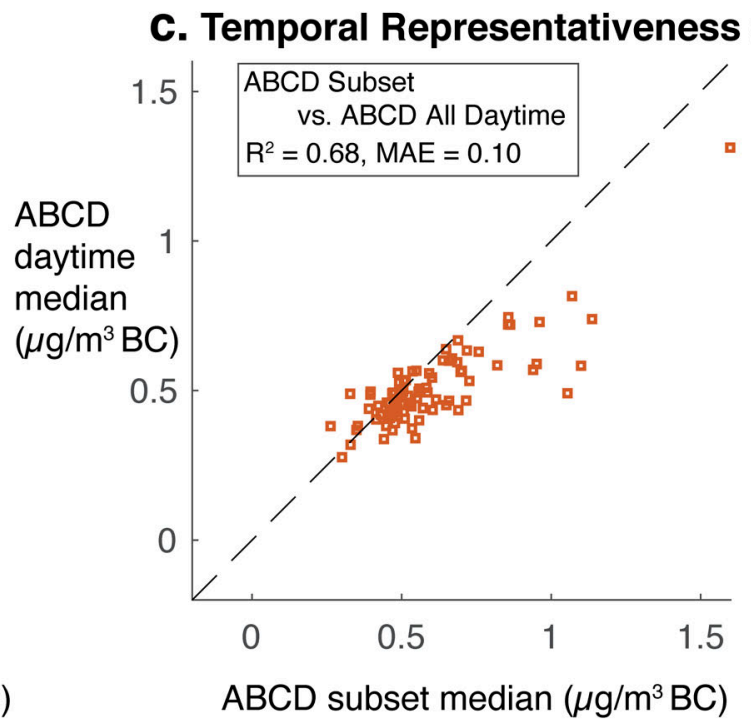

\section{b. Contemporaneous (ii)}

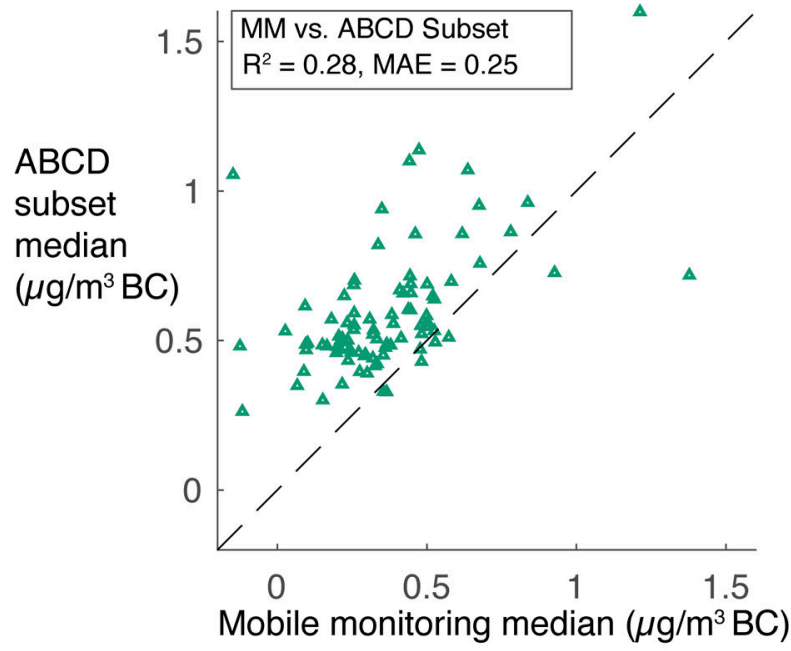

Total MM sampling time: $8.6 \mathrm{hr}$

Median visit count per site: 24

Median visit length: $6 \mathrm{~s}$

Median time per site: $3.3 \mathrm{~min}$

Median PAX precision: $0.26 \mu \mathrm{g} / \mathrm{m}^{3}$

Figure S9. Using a fixed-site radius of $30 \mathrm{~m}$, pairwise correlation between median BC concentrations measured by three distinct datasets: mobile monitoring visits (MM), ABCD measurements made during all daytime hours throughout the campaign (ABCD All Daytime), and the temporal subset of $\mathrm{ABCD}$ measurements made during mobile monitoring visits (ABCD subset). Figure S9a shows results for the core analysis with the median LOD for PAX mobile measurements indicated by the pink dotted line. Given nearly continuous monitoring, the LOD for $\mathrm{ABCD}$ daytime medians is $<<0.01 \mu \mathrm{g} \mathrm{m}^{-3}$. Figure $\mathrm{S} 9 \mathrm{~b}$ shows the first supplemental comparison: mobile monitoring medians compared with the medians of ABCD measurements made concurrently with mobile lab visits to each site (contemporaneous subsample). The mobile monitoring LOD is the same as in 3a, and the LOD for ABCD subset medians is approximately $0.1 \mu \mathrm{g} \mathrm{m}^{-3}$. Figure S9c shows the second supplemental comparison: the subsample of ABCD medians calculated during mobile lab visits compared with the medians from the complete set of daytime measurements. 


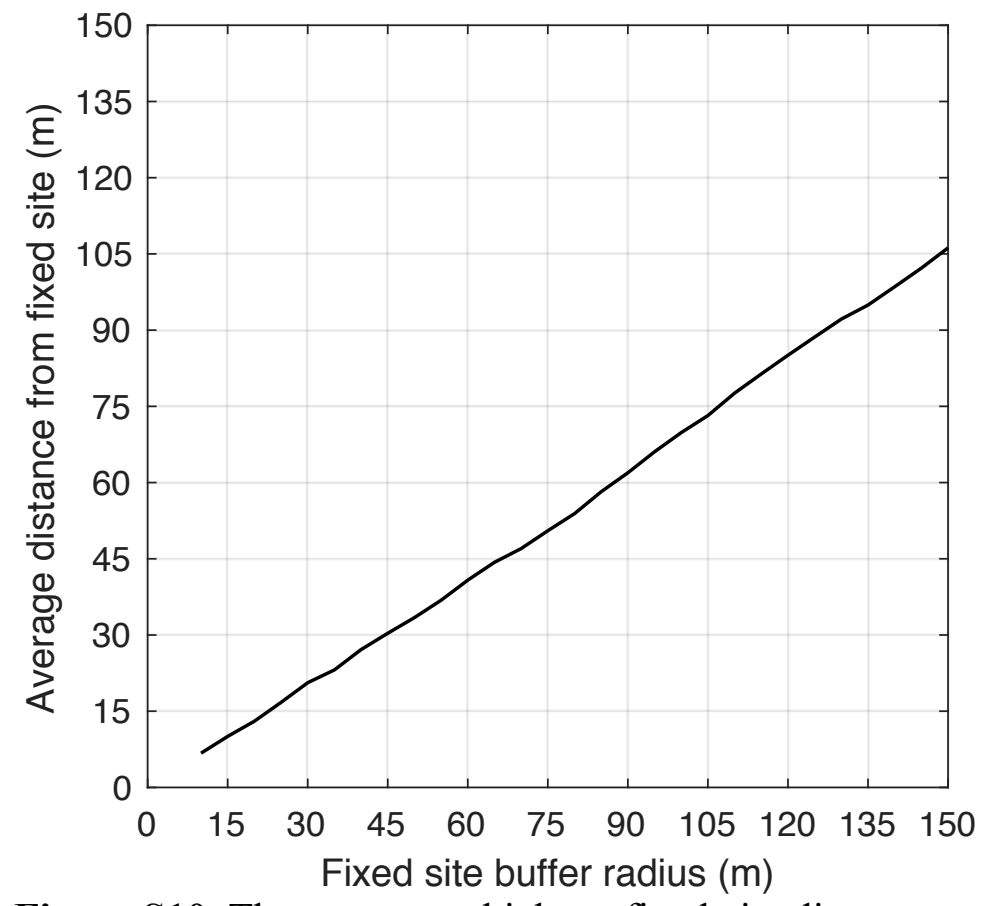

Figure S10. The average vehicle-to-fixed-site distance as a function of buffer size. Because the buffer radius indicates the maximum distance of mobile measurements from the fixed sites, many of the included measurements are made closer to the fixed site. The average distance increases at a slower rate than the increase in buffer size (slope $<1$ ). 


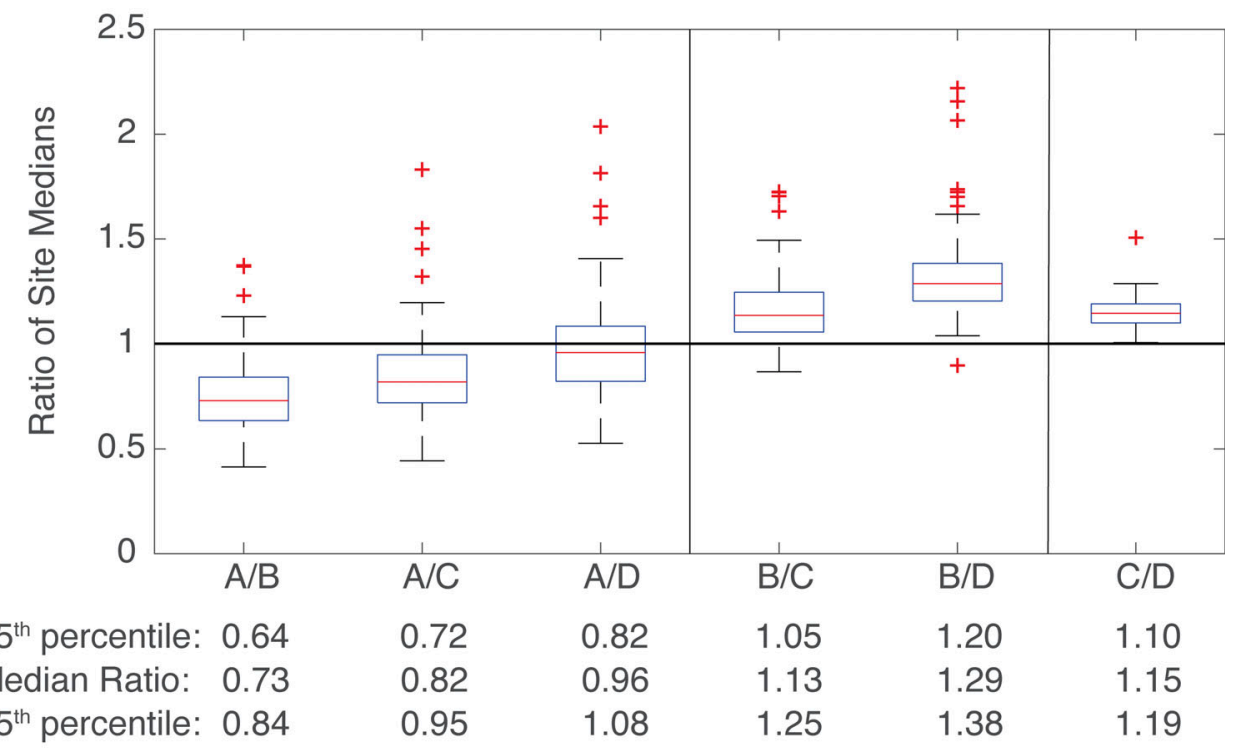

Figure S11. Supplementary temporal representativeness comparison. Each box and whisker plot shows the distribution of ratios of among five sets of site medians: A, mobile monitoring daytime medians; B, medians of fixed-site temporal subset during daytime mobile monitoring; $\mathrm{C}$, fixedsite 100-day daytime medians; $\mathrm{D}$, fixed-site 100-day overall medians 
a. Weekday daytime median BC

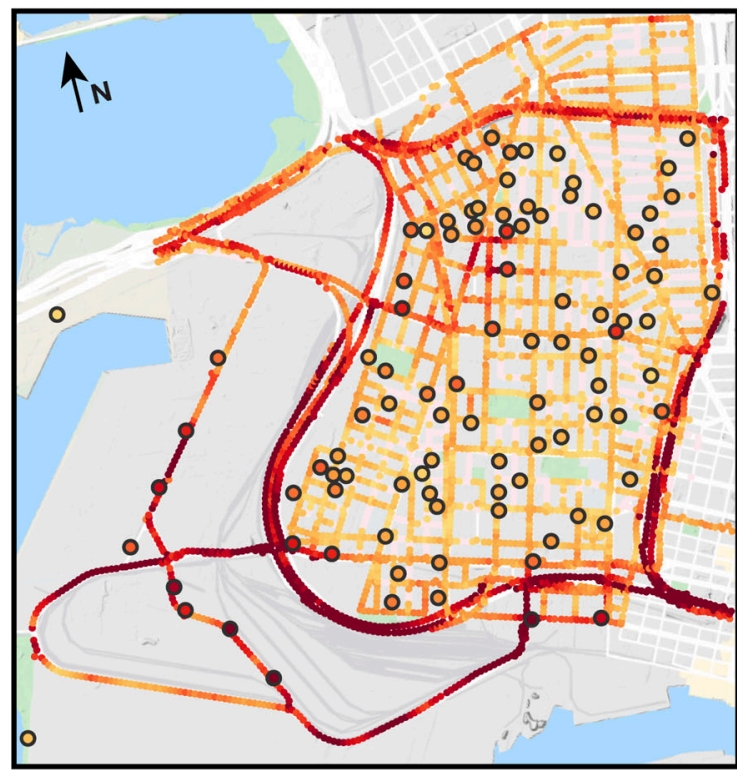

Median BC

Concentration $\left(\mu \mathrm{g} / \mathrm{m}^{3}\right)$

\section{b. Weekend daytime median BC}
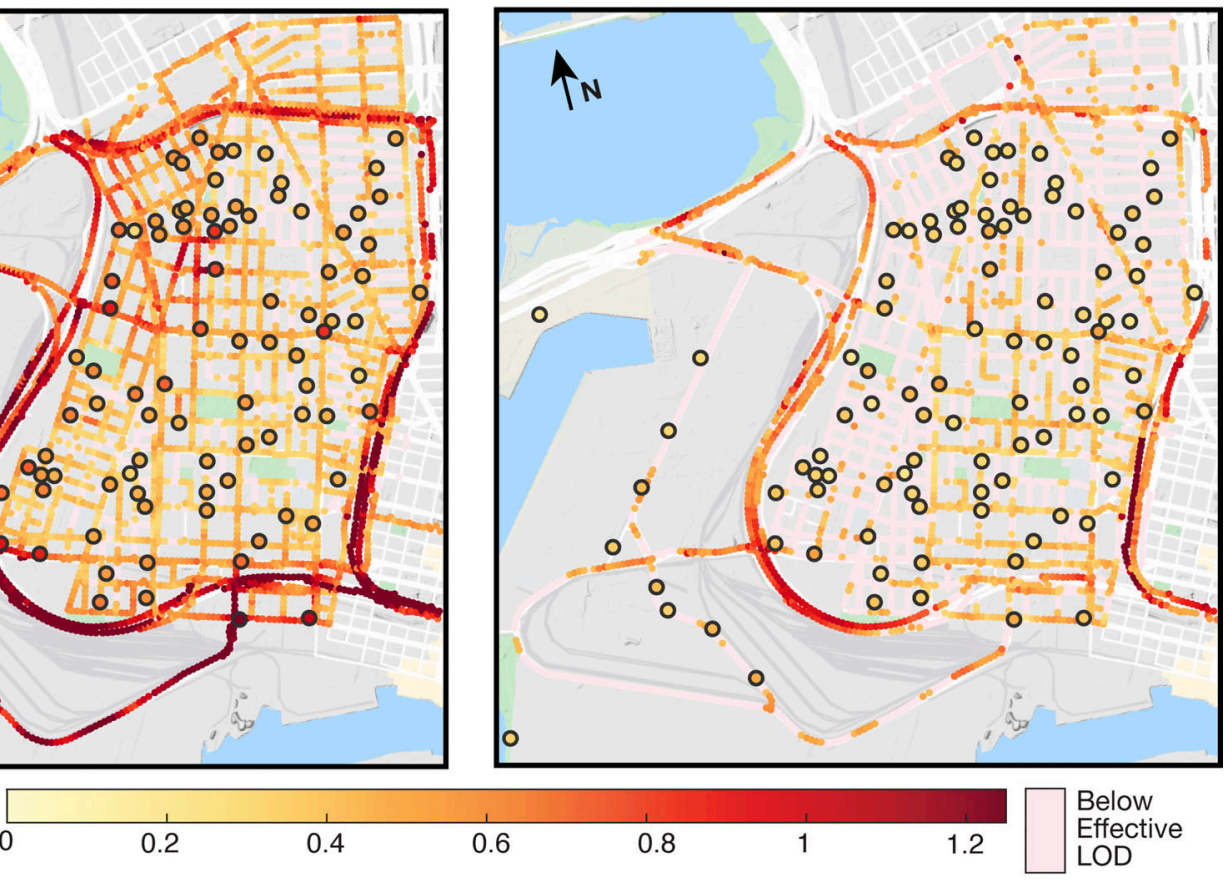

ABCD

Figure S12. Median black carbon concentration measured during daytime hours (9 am $-5 \mathrm{pm})$ throughout 100-day campaign, separated by weekday and weekend driving. Circles represent median ABCD measurements at fixed sites and on-road coloration shows smoothed mobile monitoring data (20 s moving average), represented as the median of drive-pass means calculated for $30 \mathrm{~m}$ road segments. Map data (C) 2020 Google. 


\section{a. $30 \mathrm{~m}$ buffer}

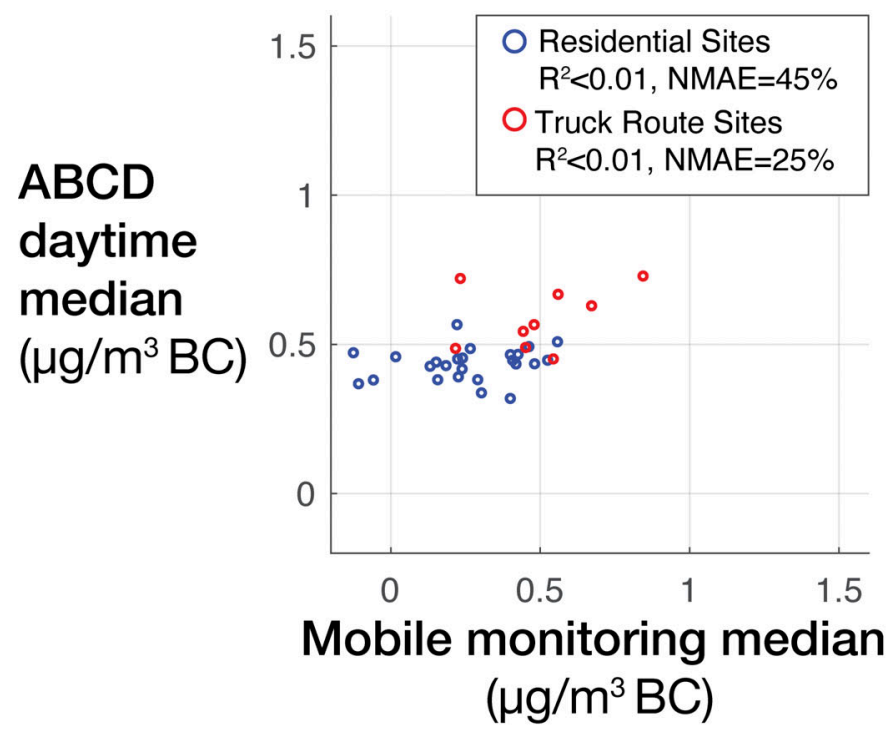

b. $95 \mathrm{~m}$ buffer

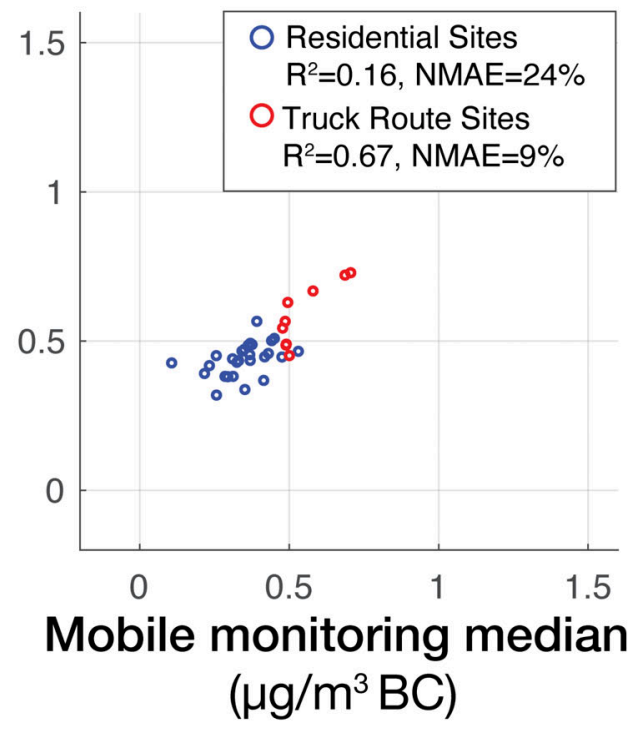

Figure S13. Core results for a subsample of $\mathrm{ABCD}$ sites based on two land use categories: residential and truck route. Figure S12a shows results at a buffer distance of $30 \mathrm{~m}$, while Figure $\mathrm{S} 12 \mathrm{~b}$ shows results at a buffer distance of $95 \mathrm{~m}$. The legend includes both the adjusted Pearson $\mathrm{R}^{2}$ and the normalized mean absolute error (NMAE). The truck route subsample excludes one outlier that had an outsized effect on correlation coefficient; with this point included, at a $30 \mathrm{~m}$ buffer $\mathrm{R}^{2}=0.77$, at a $95 \mathrm{~m}$ buffer $\mathrm{R}^{2}=0.91$.

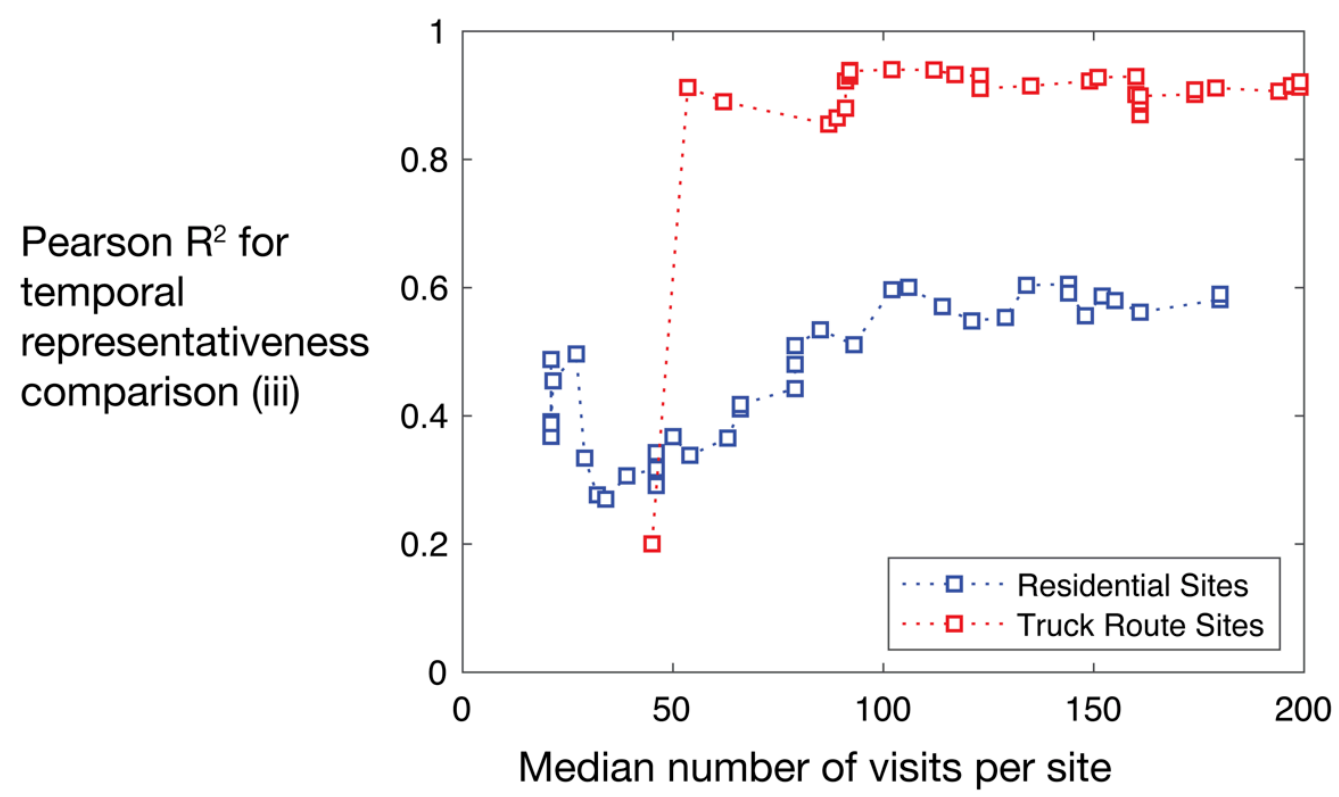

Figure S14. Correlation coefficient from the temporal representativeness comparison (iii) as a function of the median number of visits to each site. Each visit represents at least $1 \mathrm{~min}$ of $\mathrm{ABCD}$ measurements. Results are shown for two subsamples of $\mathrm{ABCD}$ sites based on two land use categories: residential and truck route. 


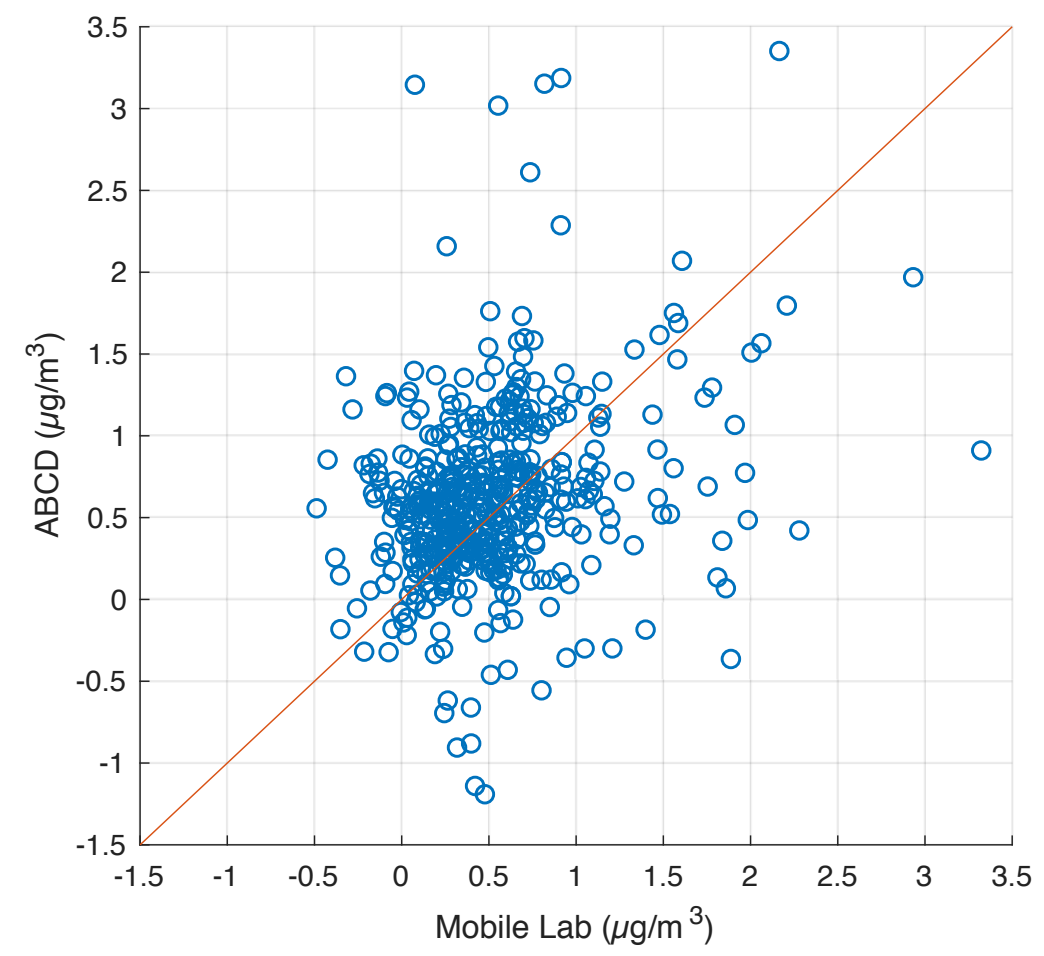

Figure S15. In-motion co-location, mobile lab vs. ABCD, at a selection of two sites that were also equipped with AE33 reference instruments. Comparison statistics include $\mathrm{R}^{2}=0.05$ and $\mathrm{MAE}=0.48 \mu \mathrm{g} \mathrm{m}^{-3}$ (see Table S7). Data for this comparison are based on visits to sites 3 and 4 while the mobile lab was in motion (speed $>0$ ) within $80 \mathrm{~m}$ of either site. The median duration of each individual visit was 17 seconds. $\mathrm{ABCD}$ values are calculated as the average of $0.5 \mathrm{~Hz}$ measurements by all ABCD sensors at a site for the duration of the in-motion visit. 


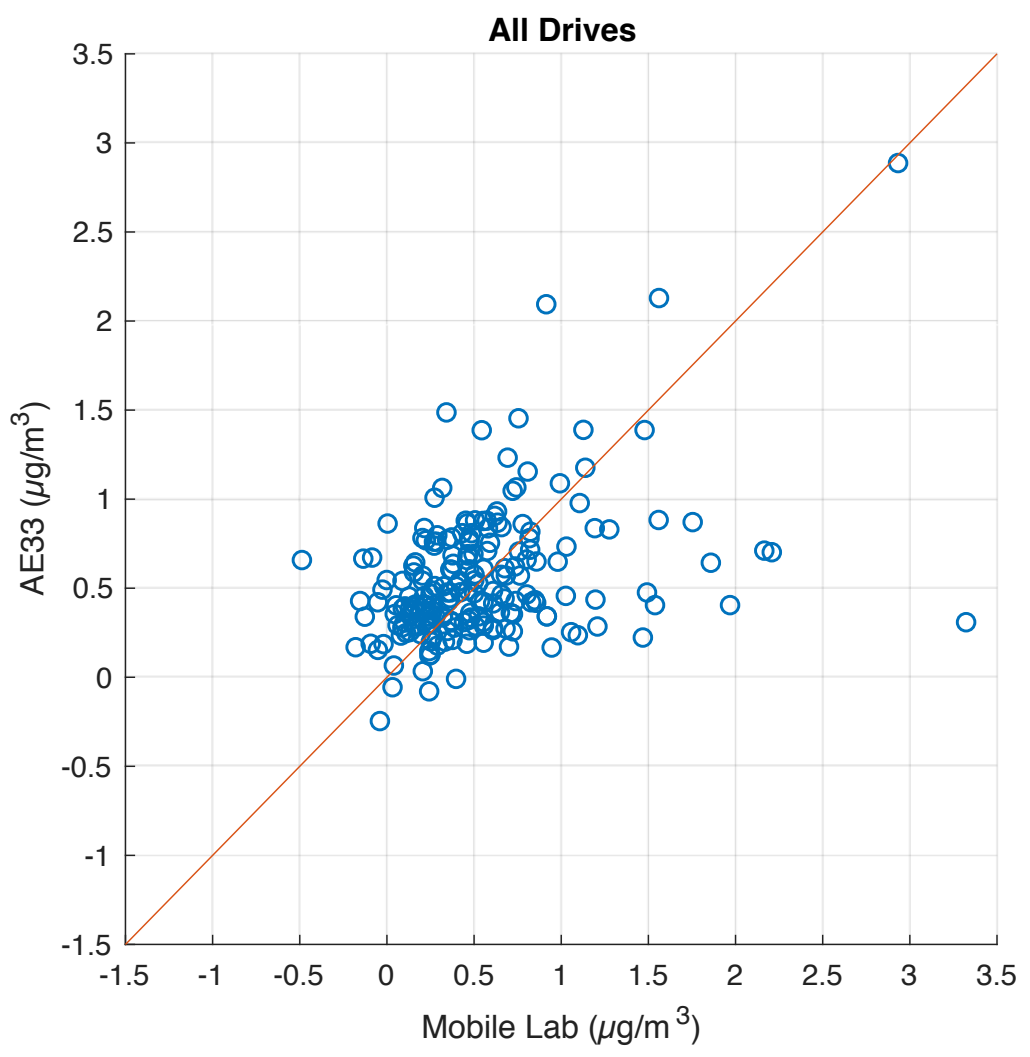

Figure S16. In-motion co-location, mobile lab vs. AE33. Comparison statistics include $\mathrm{R}^{2}=0.16$ and MAE $=0.34 \mu \mathrm{g} \mathrm{m}^{-3}$ (see Table S8). Data for this comparison are based on visits to sites 3 and 4 while the mobile lab was in motion (speed $>0$ ) within $80 \mathrm{~m}$ of either site; these data are a subset of the data presented in Figure S12, as AE33 measurements were not available for all visits. The median duration of each individual visit was 28 seconds. Because AE33 measured at 1 min intervals, values are the closest 1 min measurement to the mobile lab visit period. The higher correlation in Figure S13 vs. S12 reflects the higher precision of 1 min average AE33 measurements relative to the instantaneous $0.5 \mathrm{~Hz}$ ABCD measurements. 


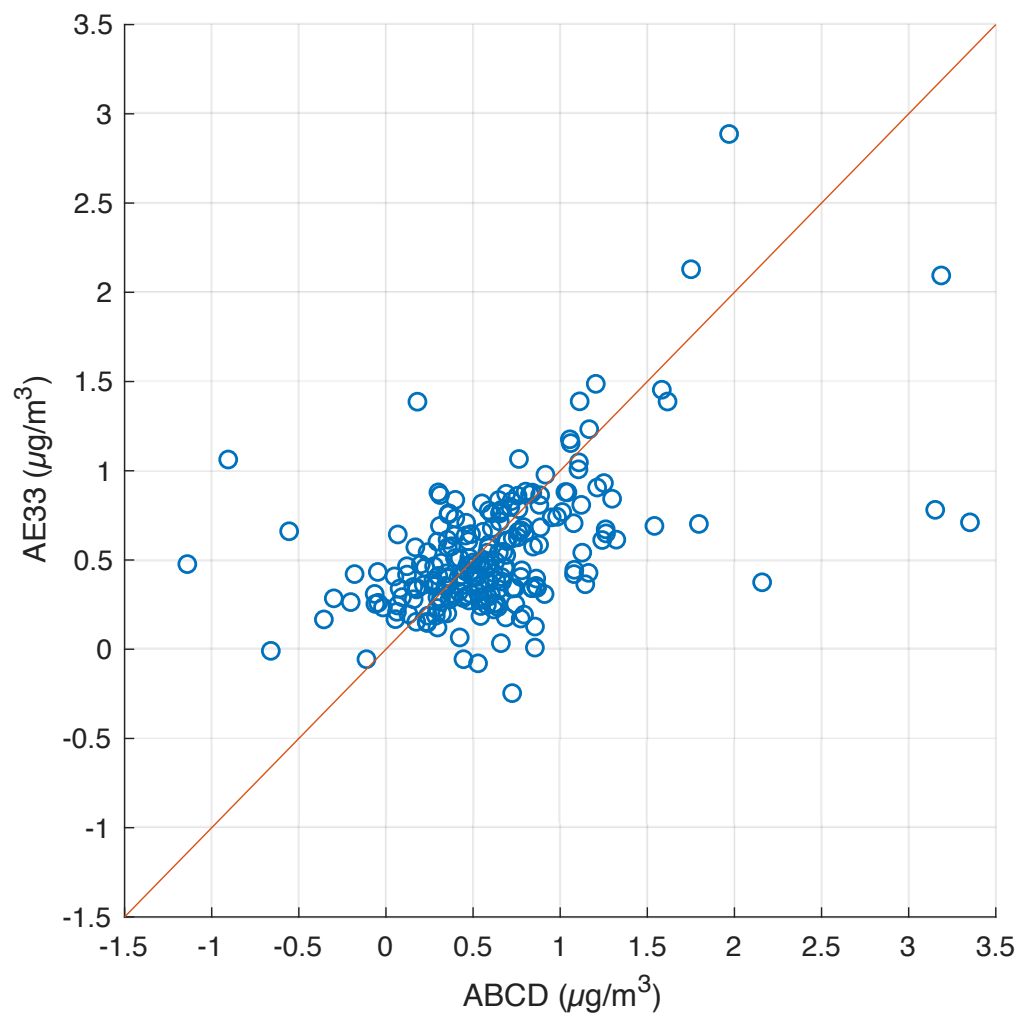

Figure S17. Comparison of the subsample of ABCD and AE33 measurements during vehicle inmotion co-location. Comparison statistics include $\mathrm{R}^{2}=0.24$ and MAE $=0.31 \mu \mathrm{g} \mathrm{m}^{-3}$ (see Table S9). Data for this comparison are based on the subsample of ABCD and AE33 data during times when the mobile lab was in motion (speed $>0$ ) within $80 \mathrm{~m}$ of site 3 or site 4 . The median duration of each individual visit was 28 seconds. ABCD values are calculated as the average of $0.5 \mathrm{~Hz}$ measurements by all ABCD sensors at a site for the duration of the in-motion visit. Because AE33 measured at 1 min intervals, values are the closest 1 min measurement to the mobile lab visit period. Because ABCD instruments were operated in direct proximity to the AE33 instrument at each site, correlation is higher for the comparison in Figure S14 than comparisons against mobile laboratory measurements in Figure S12 and S13. 


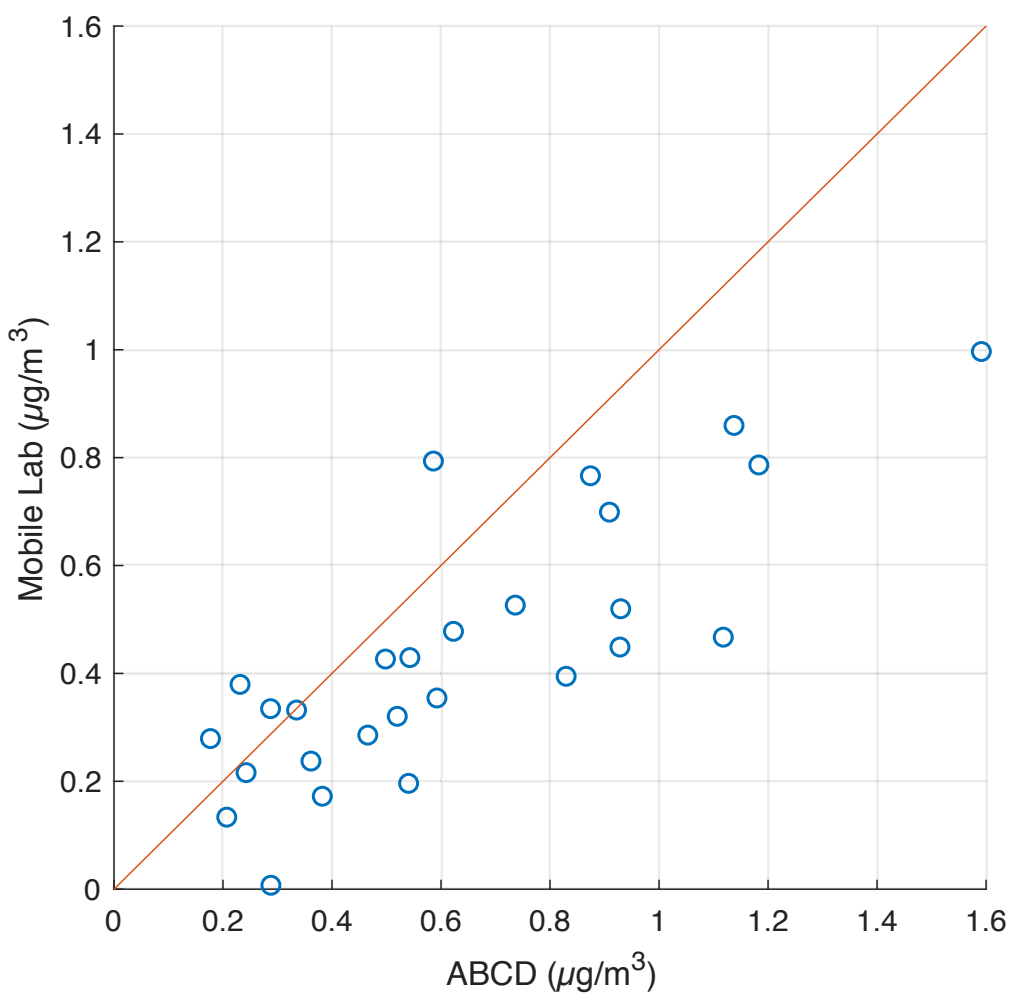

Figure S18. Short-term stationary co-location, ABCD vs. mobile lab. Data for this comparison are based on visits to sites 3 and 4 while the mobile lab was parked (speed $=0$ ) for at least 60 seconds within $80 \mathrm{~m}$ of either site. ABCD values are calculated as the average of $0.5 \mathrm{~Hz}$ measurements by all ABCD sensors at a site for the duration of the co-location. The median duration of each stationary visit was 7.25 minutes. This comparison shows a dramatic improvement in correlation compared to Figure $\mathrm{S} 12\left(\mathrm{R}^{2}=0.65\right.$, see Table S10), as the increased averaging time for both $\mathrm{PAX}$ and $\mathrm{ABCD}$ instruments provides more stable estimates of shortterm concentration conditions. 


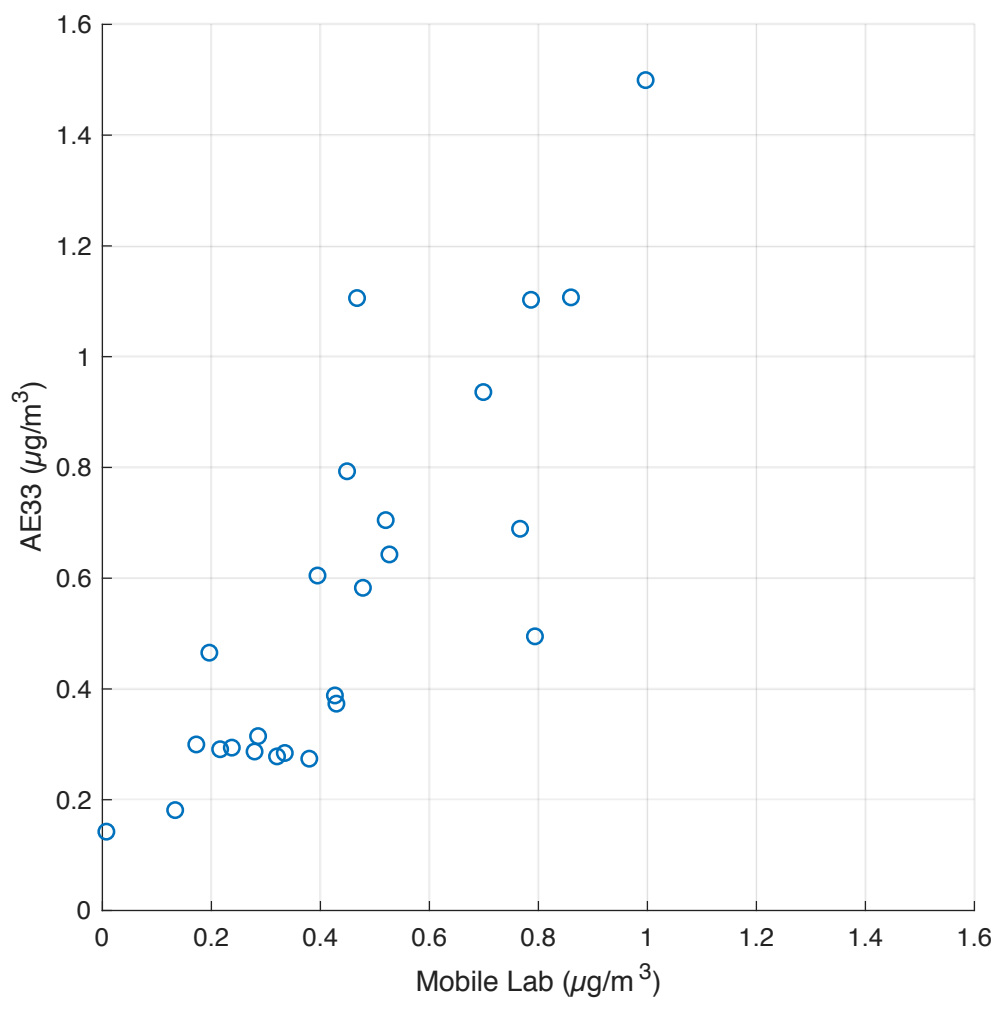

Figure S19. Short-term stationary co-location, mobile lab vs. AE33. Data for this comparison are based on visits to sites 3 and 4 while the mobile lab was parked (speed $=0$ ) for at least 60 seconds within $80 \mathrm{~m}$ of either site. The median duration of each stationary visit was 7.25 minutes. As with the data shown in Figure S16, the increased averaging time provides more stable estimates of short-term concentration conditions and dramatically increases correlation $\left(\mathrm{R}^{2}\right.$ $=0.67$, see Table S11). 


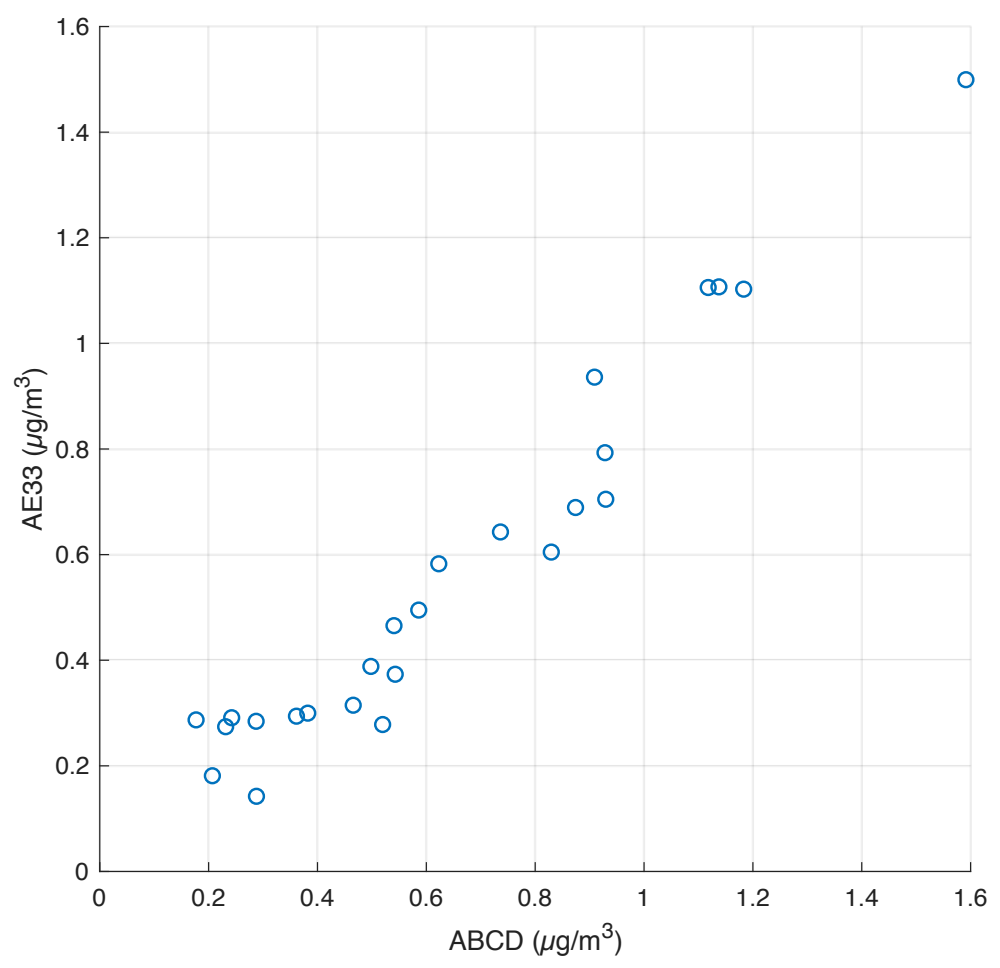

Figure S20. Comparison of the subsample of ABCD and AE33 measurements during vehicle short-term stationary co-location. Data for this comparison are based on the subsample of ABCD and AE33 data during times when the mobile lab was parked (speed $=0$ ) for at least 60 seconds within $80 \mathrm{~m}$ of site 3 or site 4. Median visit length: 7.25 minutes. ABCD values are calculated as the average of $0.5 \mathrm{~Hz}$ measurements by all ABCD sensors at a site for the duration of the colocation. The ABCD and AE33 instruments agree closely with one another, $\mathrm{R}^{2}=0.94$ and MAE $=0.1 \mu \mathrm{g} \mathrm{m}^{-3}$ (see Table S12). 
S4. Supporting Information Tables

Table S1. Black carbon detection methods in recent mobile monitoring campaigns ${ }^{2-14}$

\begin{tabular}{|c|c|c|c|c|}
\hline Instrument & $\begin{array}{c}\text { Time } \\
\text { resolution }\end{array}$ & Study & Avg. Speed & Minimum spatial unit \\
\hline \multicolumn{5}{|c|}{ Aethalometer (Magee Scientific) } \\
\hline AE16 & $1 / \mathrm{min}$ & $\begin{array}{l}\text { Padro-Martinez et } \\
\text { al. 2012, } \\
\text { Patton et al. } 2014\end{array}$ & - & $\begin{array}{c}\text { Binned data by distance from } \\
\text { highway }\end{array}$ \\
\hline \multirow[t]{3}{*}{ AE33 } & $1 / \mathrm{min}$ & Shah et al. 2018 & $10 \mathrm{~m} / \mathrm{s}$ & $30 \mathrm{~m}$ road segment \\
\hline & $1 / \min$ & Li et al. 2019 & - & 100x100 m grid cell \\
\hline & $1 / \mathrm{s}$ & Miller et al. 2020 & $\begin{array}{l}\text { Used speed } \\
\text { distribution to } \\
\text { determine } \\
\text { spatial unit }\end{array}$ & $\begin{array}{l}15-72 \mathrm{~m} \text { on surface streets, } \\
62-170 \mathrm{~m} \text { on highways }\end{array}$ \\
\hline AE42 & $1 / \mathrm{s}^{\mathrm{a}}$ & Brantley et al. 2013 & $10 \mathrm{~m} / \mathrm{s}$ & $10 \mathrm{~m}$ road segment \\
\hline \multicolumn{5}{|c|}{ Micro-Aethalometer (Aethlabs, Incorporated) } \\
\hline \multirow[t]{4}{*}{ AE51 } & $1 / \mathrm{s}$ & Apte et al. 2011 & - & Route $(34-37 \mathrm{~km})$ \\
\hline & $1 / \mathrm{s}$ & $\begin{array}{l}\text { Van Poppel et al. } \\
2013\end{array}$ & $2.7 \mathrm{~m} / \mathrm{s}$ & $\begin{array}{c}\text { Route segment ("zone"), } \\
\text { length }>100 \mathrm{~m}\end{array}$ \\
\hline & $1 / \mathrm{s}$ & Peters et al. $2014^{\mathrm{b}}$ & Not given & $10 \mathrm{~m}$ road segment \\
\hline & $1 / \mathrm{s}$ & $\begin{array}{l}\text { Van Den Bossche } \\
\text { et al. } 2015^{\mathrm{c}}\end{array}$ & $3.2 \mathrm{~m} / \mathrm{s}$ & $20 \mathrm{~m}$ road segment \\
\hline $\begin{array}{c}\text { Model not } \\
\text { specified }\end{array}$ & $1 / \mathrm{min}$ & $\begin{array}{l}\text { Kerckhoffs et al. } \\
2016^{\mathrm{d}}\end{array}$ & - & $\begin{array}{l}\text { Variably sized road segment, } \\
\text { average length }=130 \mathrm{~m}\end{array}$ \\
\hline \multicolumn{5}{|c|}{ Multi-Angle Absorption Photometer, MAAP (Thermo Scientific) } \\
\hline 5012 & $1 / \mathrm{min}$ & Tan et al. 2014 & - & $500 \times 500 \mathrm{~m}$ grid cell \\
\hline \multicolumn{5}{|c|}{ Photoacoustic Extinctiometer, PAX (Droplet Measurement Technologies) } \\
\hline & $1 / \mathrm{s}$ & Levy et al. 2014 & $5.5-8.3 \mathrm{~m} / \mathrm{s}$ & $20 \mathrm{~m}$ road segment $\mathrm{e}^{\mathrm{e}}$ \\
\hline & $1 / \mathrm{s}$ & Apte et al. 2017 & $\begin{array}{c}7-24 \mathrm{~m} / \mathrm{s} \\
\text { (residential road } \\
\text { vs. highway) }\end{array}$ & $30 \mathrm{~m}$ road segment \\
\hline
\end{tabular}

${ }^{2}$ Miller et al. (2020) distinguish between the time resolution of data reported by the Aethalometer, $1 \mathrm{~s}$, and the instrument response time (e-folding time for a step change in concentration, $\leq 5 \mathrm{~s}$; the instrument response time is the determining factor for the maximum spatial resolution from mobile measurements, not reporting time.

${ }^{b}$ Peters et al. (2014) included a comparison between continuous fixed-site measurements at a background location with daily mobile $\mathrm{BC}$ data.

${ }^{\mathrm{c}}$ Among all studies reviewed, only Van Den Bossche et al. (2015) included a comparison between continuous fixedsite measurements and localized mobile monitoring.

${ }^{\mathrm{d}}$ Kerckhoffs et al. (2016) performed short-term stationary measurements to create a pseudo co-location comparison but did not include $\mathrm{BC}$ due to the constraint on spatial resolution caused by the temporal resolution of $\mathrm{BC}$ measurements.

${ }^{\mathrm{e}}$ Although Levy et al. (2014) noted that data were processed to this spatial scale, the featured analyses were conducted on more spatially aggregated data 
Table S2. Agreement between PAX instruments ${ }^{a}$

\begin{tabular}{lrrrrrrr}
\hline Averaging Period & $\mathrm{R}^{2}$ & Slope & $\begin{array}{c}\text { Intercept } \\
\left(\mu \mathrm{g} / \mathrm{m}^{3}\right)\end{array}$ & $\begin{array}{r}\text { RMSE } \\
\left(\mu \mathrm{g} / \mathrm{m}^{3}\right)\end{array}$ & NRMSE & $\begin{array}{r}\text { MBE } \\
\left(\mu \mathrm{g} / \mathrm{m}^{3}\right)\end{array}$ & $\begin{array}{r}\text { MAE } \\
\left(\mu \mathrm{g} / \mathrm{m}^{3}\right)\end{array}$ \\
\hline 1 minute & 0.92 & 1.02 & -0.03 & 0.22 & 0.29 & -0.05 & 0.13 \\
20 minutes & 0.97 & 1.05 & -0.05 & 0.12 & 0.15 & -0.02 & 0.08 \\
\hline
\end{tabular}

${ }^{a}$ To harmonize measurements among PAX instruments, both mobile laboratory PAX instruments were co-located with a third PAX instrument and linear corrections derived from colocation data were applied to measurements from PAX $1(0.78 \mathrm{x}-0.16)$ and PAX $2(1.17 \mathrm{x}+$ $0.04)$.

Table S3. Pairwise correlation among co-located PAX and ABCD instruments at a $1 \mathrm{~min}$ averaging period $(\mathrm{N}=6400)$.

\begin{tabular}{llrrrrrrr}
\hline & & $\mathrm{R}^{2}$ & Slope & $\begin{array}{c}\text { Intercept } \\
\left(\mu \mathrm{g} / \mathrm{m}^{3}\right)\end{array}$ & $\begin{array}{r}\text { RMSE } \\
\left(\mu \mathrm{g} / \mathrm{m}^{3}\right)\end{array}$ & NRMSE & $\begin{array}{r}\text { MBE } \\
\left(\mu \mathrm{g} / \mathrm{m}^{3}\right)\end{array}$ & $\begin{array}{r}\text { MAE } \\
\left(\mu \mathrm{g} / \mathrm{m}^{3}\right)\end{array}$ \\
\hline PAX 1 & ABCD 1 & 0.86 & 1.10 & -0.05 & 0.33 & 0.41 & 0.03 & 0.21 \\
& ABCD 2 & 0.72 & 1.13 & -0.05 & 0.50 & 0.61 & 0.05 & 0.23 \\
& ABCD 3 & 0.86 & 1.09 & -0.07 & 0.32 & 0.41 & 0.00 & 0.22 \\
\hline PAX 2 & ABCD 1 & 0.84 & 1.02 & 0.02 & 0.35 & 0.44 & 0.04 & 0.21 \\
& ABCD 2 & 0.64 & 1.05 & 0.03 & 0.61 & 0.74 & 0.06 & 0.23 \\
& ABCD 3 & 0.83 & 1.01 & 0.02 & 0.35 & 0.45 & 0.02 & 0.22 \\
\hline PAX average & ABCD average & 0.83 & 1.08 & -0.03 & 0.35 & 0.45 & 0.03 & 0.19 \\
\hline
\end{tabular}

Table S4. Pairwise correlation among co-located PAX and ABCD instruments at a $20 \mathrm{~min}$ averaging period $(\mathrm{N}=320)$.

\begin{tabular}{llrrrrrrr}
\hline & & $\mathrm{R}^{2}$ & Slope & $\begin{array}{c}\text { Intercept } \\
\left(\mu \mathrm{g} / \mathrm{m}^{3}\right)\end{array}$ & $\begin{array}{r}\text { RMSE } \\
\left(\mu \mathrm{g} / \mathrm{m}^{3}\right)\end{array}$ & NRMSE & $\begin{array}{c}\text { MBE } \\
\left(\mu \mathrm{g} / \mathrm{m}^{3}\right)\end{array}$ & $\begin{array}{c}\text { MAE } \\
\left(\mu \mathrm{g} / \mathrm{m}^{3}\right)\end{array}$ \\
\hline PAX 1 & ABCD 1 & 0.91 & 1.13 & -0.08 & 0.26 & 0.32 & 0.02 & 0.17 \\
& ABCD 2 & 0.87 & 1.16 & -0.07 & 0.33 & 0.39 & 0.05 & 0.18 \\
& ABCD 3 & 0.91 & 1.12 & -0.09 & 0.25 & 0.32 & 0.00 & 0.17 \\
\hline \multirow{2}{*}{ PAX 2 } & ABCD 1 & 0.90 & 1.06 & -0.01 & 0.26 & 0.33 & 0.04 & 0.16 \\
& ABCD 2 & 0.85 & 1.08 & 0.00 & 0.33 & 0.39 & 0.06 & 0.17 \\
& ABCD 3 & 0.90 & 1.05 & -0.02 & 0.25 & 0.32 & 0.02 & 0.15 \\
\hline PAX average & ABCD average & 0.90 & 1.11 & -0.05 & 0.26 & 0.32 & 0.03 & 0.16 \\
\hline
\end{tabular}


Table S5. Regressions of median mobile monitoring and ABCD visit means by weekend and weekday with a fixed-site buffer length of $95 \mathrm{~m}$.

\begin{tabular}{llrrr}
\hline & $\begin{array}{c}\text { Cumulative } \\
\text { Sampling Duration }\end{array}$ & $\begin{array}{r}\text { RMSE } \\
\left(\mu \mathrm{g} \mathrm{m}^{-3} \mathrm{BC}\right)\end{array}$ & NRMSE \\
\hline Weekday & 40.4 hours & 0.45 & 0.18 & $33 \%$ \\
Weekend & 15.3 hours & 0.03 & 0.13 & $35 \%$ \\
\hline
\end{tabular}

Table S6. Spatiotemporal comparison: mobile monitoring and ABCD visit means

\begin{tabular}{lrrrr}
\hline Buffer length $(\mathrm{m})$ & $\mathrm{R}^{2 a}$ & $\begin{array}{r}\text { RMSE } \\
\left(\mu \mathrm{g} \mathrm{m}^{-3} \mathrm{BC}\right)\end{array}$ & NRMSE & $\mathrm{N}^{b}$ \\
\hline 15 & 0.04 & 1.45 & $215 \%$ & 930 \\
30 & 0.05 & 1.38 & $190 \%$ & 2431 \\
60 & 0.02 & 1.46 & $212 \%$ & 4314 \\
90 & $<0.01$ & 2.02 & $304 \%$ & 5977 \\
120 & $<0.01$ & 2.69 & $416 \%$ & 8150 \\
150 & $<0.01$ & 2.17 & $304 \%$ & 9955 \\
\hline
\end{tabular}

${ }^{a}$ While many spatial and temporal factors may cause disagreement between contemporaneous measurements, instrument noise is a dominant factor: at the 15 s timescale of a visit within a $95 \mathrm{~m}$ buffer, the estimated PAX LOD of $0.6 \mu \mathrm{g} / \mathrm{m}^{3}$ exceeds $60 \%$ of visit mean concentrations.

${ }^{b}$ Number of unique visits.

Table S7. Sensitivity to elevated background concentration due to long-range transport (LRT) pollution events

\begin{tabular}{lrrrr} 
Metric & \multicolumn{2}{c}{$\begin{array}{l}\text { Core comparison results } \\
\text { (Mobile monitoring vs. } \\
\text { ABCD campaign) }\end{array}$} & $\begin{array}{r}\text { Contemporaneous subsample } \\
\text { results (Mobile monitoring vs. } \\
\text { ABCD visit measurements) }\end{array}$ \\
\hline $\mathrm{R}^{2}$ & All days & $\begin{array}{r}\text { LRT Events } \\
\text { Excluded }\end{array}$ & All days & $\begin{array}{r}\text { LRT Events } \\
\text { Excluded }\end{array}$ \\
$\mathrm{RMSE}$ & 0.51 & 0.53 & 0.49 & 0.50 \\
$\mathrm{MAE}$ & $0.13 \mu \mathrm{g} / \mathrm{m}^{3}$ & $0.12 \mu \mathrm{g} / \mathrm{m}^{3}$ & $0.21 \mu \mathrm{g} / \mathrm{m}^{3}$ & $0.21 \mu \mathrm{g} / \mathrm{m}^{3}$ \\
$\mathrm{MBE}$ & $0.11 \mu \mathrm{g} / \mathrm{m}^{3}$ & $0.10 \mu \mathrm{g} / \mathrm{m}^{3}$ & $0.17 \mu \mathrm{g} / \mathrm{m}^{3}$ & $0.18 \mu \mathrm{g} / \mathrm{m}^{3}$ \\
& $0.08 \mu \mathrm{g} / \mathrm{m}^{3}$ & $0.06 \mu \mathrm{g} / \mathrm{m}^{3}$ & $0.16 \mu \mathrm{g} / \mathrm{m}^{3}$ & $0.16 \mu \mathrm{g} / \mathrm{m}^{3}$ \\
\hline
\end{tabular}


Table S7. Mobile lab vs. ABCD during in-motion visits ${ }^{a}$

\begin{tabular}{|c|c|c|c|c|c|}
\hline & $\begin{array}{l}\text { Both } \\
\text { sites }\end{array}$ & $\begin{array}{l}\text { Site } \\
3 \\
\text { only }\end{array}$ & $\begin{array}{l}\text { Site } \\
4 \\
\text { only }\end{array}$ & $\begin{array}{l}\text { Vehicle } \\
1\end{array}$ & $\begin{array}{l}\text { Vehicle } \\
2\end{array}$ \\
\hline $\mathbf{N}$ visits & 486 & 189 & 297 & 160 & 326 \\
\hline $\begin{array}{r}\text { Total } \\
\text { time } \\
\text { (min) }\end{array}$ & 200 & 83 & 118 & 64 & 136 \\
\hline $\mathbf{R}^{2}$ & 0.05 & 0.04 & 0.08 & 0.08 & 0.04 \\
\hline Slope & 0.18 & 0.13 & 0.30 & 0.25 & 0.14 \\
\hline Intercept & 0.41 & 0.53 & 0.28 & 0.42 & 0.41 \\
\hline RMSE & 0.71 & 0.92 & 0.54 & 0.71 & 0.72 \\
\hline MAE & 0.48 & 0.60 & 0.40 & 0.48 & 0.47 \\
\hline MBE & -0.08 & 0.01 & $0.13^{-}$ & -0.03 & -0.11 \\
\hline
\end{tabular}

${ }^{a}$ Data for this comparison are based on visits to sites 3 and 4 while the mobile lab was in motion (speed $>0$ ) within $80 \mathrm{~m}$ of either site. Median visit length: 17 seconds. ABCD values are calculated as the average of $0.5 \mathrm{~Hz}$ measurements by all ABCD sensors at a site for the duration of the in-motion visit.

Table S8. Mobile lab vs. AE33 during in-motion visits ${ }^{a}$

\begin{tabular}{|c|c|c|c|c|c|}
\hline & $\begin{array}{l}\text { Both } \\
\text { sites }\end{array}$ & $\begin{array}{l}\text { Site } \\
3 \\
\text { only }\end{array}$ & $\begin{array}{l}\text { Site } \\
4 \\
\text { only }\end{array}$ & $\begin{array}{l}\text { Vehicle } \\
1\end{array}$ & $\begin{array}{l}\text { Vehicle } \\
2\end{array}$ \\
\hline $\mathbf{N}$ visits & 206 & 96 & 110 & 62 & 144 \\
\hline $\begin{array}{r}\text { Total } \\
\text { time } \\
\text { (min) }\end{array}$ & 118 & 58 & 60 & 37 & 81 \\
\hline $\mathbf{R}^{2}$ & 0.16 & 0.03 & 0.41 & 0.34 & 0.07 \\
\hline Slope & 0.30 & 0.13 & 0.56 & 0.42 & 0.21 \\
\hline Intercept & 0.39 & 0.48 & 0.28 & 0.32 & 0.44 \\
\hline RMSE & 0.49 & 0.61 & 0.35 & 0.47 & 0.49 \\
\hline МАE & 0.34 & 0.42 & 0.27 & 0.34 & 0.34 \\
\hline MBE & 0.02 & 0.06 & 0.09 & -0.00 & 0.03 \\
\hline
\end{tabular}

${ }^{a}$ Data for this comparison are based on visits to sites 3 and 4 while the mobile lab was in motion (speed $>0$ ) within $80 \mathrm{~m}$ of either site. Median visit length: 28 seconds. AE33 values are the closest 1 min measurement to the mobile lab visit period. 
Table S9. AE33 vs. ABCD temporal subsample based on in-motion visits ${ }^{a}$

\begin{tabular}{r|lll} 
& $\begin{array}{l}\text { Both } \\
\text { sites }\end{array}$ & Site & Site \\
\hline N visits & $\mathbf{2 1 8}$ & 102 & 116 \\
Total & $\mathbf{1 1 8}$ & 58 & 60 \\
time & & & \\
(min) & & & \\
& & & \\
$\mathbf{R}^{2}$ & $\mathbf{0 . 2 4}$ & 0.17 & 0.39 \\
Slope & $\mathbf{0 . 3 4}$ & 0.24 & 0.55 \\
Intercept & $\mathbf{0 . 3 3}$ & 0.39 & 0.22 \\
& & & \\
RMSE & $\mathbf{0 . 4 8}$ & 0.59 & 0.35 \\
MAE & $\mathbf{0 . 3 1}$ & 0.40 & 0.24 \\
MBE & $\mathbf{- 0 . 0 7}$ & - & - \\
& & 0.10 & 0.05
\end{tabular}

${ }^{a}$ Data for this comparison are based on the subsample of $\mathrm{ABCD}$ and $\mathrm{AE} 33$ data during times when the mobile lab was in motion (speed $>0$ ) within $80 \mathrm{~m}$ of site 3 or site 4 . Median duration for each data point: 28 seconds. $\mathrm{ABCD}$ values are calculated as the average of $0.5 \mathrm{~Hz}$ measurements by all $\mathrm{ABCD}$ sensors at a site for the duration of the in-motion visit. AE33 values are the closest 1 minute measurement to the mobile lab visit period.

Table S10. ABCD vs. mobile lab during short-term stationary co-location ${ }^{a}$

\begin{tabular}{|c|c|c|c|c|c|}
\hline & $\begin{array}{l}\text { Both } \\
\text { sites }\end{array}$ & \begin{tabular}{|l|} 
Site \\
3 \\
only
\end{tabular} & $\begin{array}{l}\text { Site } \\
4 \\
\text { only }\end{array}$ & $\begin{array}{l}\text { Vehicle } \\
1\end{array}$ & $\begin{array}{l}\text { Vehicle } \\
2\end{array}$ \\
\hline $\mathrm{N}$ visits & 27 & 8 & 19 & 11 & 16 \\
\hline $\begin{array}{r}\text { Total } \\
\text { time } \\
\text { (min) }\end{array}$ & 222 & 74 & 148 & 100 & 121 \\
\hline $\mathbf{R}^{2}$ & 0.65 & 0.72 & 0.61 & 0.75 & 0.70 \\
\hline Slope & 0.55 & 0.61 & 0.53 & 0.58 & 0.74 \\
\hline Intercept & 0.09 & 0.04 & 0.11 & 0.00 & 0.04 \\
\hline RMSE & 0.29 & 0.28 & 0.29 & 0.40 & 0.17 \\
\hline MAE & 0.23 & 0.25 & 0.22 & 0.36 & 0.15 \\
\hline MBE & -0.20 & 0.22 & & -0.36 & -0.08 \\
\hline
\end{tabular}

${ }^{a}$ Data for this comparison are based on visits to sites 3 and 4 while the mobile lab was parked $($ speed $=0$ ) for at least 60 seconds within $80 \mathrm{~m}$ of either site. $A B C D$ values are calculated as the average of $0.5 \mathrm{~Hz}$ measurements by all $\mathrm{ABCD}$ sensors at a site for the duration of the. Median visit length: 7.25 minutes. 
Table S11. AE33 vs. mobile lab during short-term stationary co-location ${ }^{a}$

\begin{tabular}{|c|c|c|c|c|c|}
\hline & $\begin{array}{l}\text { Both } \\
\text { sites }\end{array}$ & $\begin{array}{l}\text { Site } \\
3 \\
\text { only }\end{array}$ & $\begin{array}{l}\text { Site } \\
4 \\
\text { only }\end{array}$ & $\begin{array}{l}\text { Vehicle } \\
1\end{array}$ & $\begin{array}{l}\text { Vehicle } \\
2\end{array}$ \\
\hline $\mathbf{N}$ visits & 25 & 8 & 17 & 11 & 14 \\
\hline $\begin{array}{r}\text { Total } \\
\text { time } \\
\text { (min) }\end{array}$ & 222 & 74 & 148 & 100 & 121 \\
\hline $\mathbf{R}^{2}$ & 0.67 & 0.82 & 0.60 & 0.71 & 0.75 \\
\hline Slope & 1.17 & 1.25 & 1.13 & 1.36 & 0.95 \\
\hline Intercept & 0.04 & 0.01 & 0.05 & 0.06 & 0.05 \\
\hline RMSE & 0.23 & 0.19 & 0.25 & 0.31 & 0.14 \\
\hline MAE & 0.17 & 0.16 & 0.18 & 0.25 & 0.03 \\
\hline MBE & 0.12 & 0.13 & 0.11 & 0.24 & 0.11 \\
\hline
\end{tabular}

${ }^{a}$ Data for this comparison are based on visits to sites 3 and 4 while the mobile lab was parked $(\mathrm{speed}=0)$ for at least 60 seconds within $80 \mathrm{~m}$ of either site. Median visit length: 7.25 minutes.

Table S12. AE33 vs. ABCD temporal subsample based on short-term stationary co-location ${ }^{a}$

\begin{tabular}{r|lll} 
& $\begin{array}{l}\text { Both } \\
\text { sites }\end{array}$ & Site & Site \\
\hline N visits & $\mathbf{2 5}$ & 8 & $\mathbf{4}$ \\
Total & $\mathbf{2 2 2}$ & 74 & 148 \\
time & & & \\
(min) & & & \\
& & & \\
$\mathbf{R}^{2}$ & $\mathbf{0 . 9 4}$ & 0.94 & 0.93 \\
Slope & $\mathbf{0 . 9 3}$ & 0.95 & 0.93 \\
Intercept & $\mathbf{- 0 . 0 4}$ & - & - \\
& & 0.05 & 0.03 \\
& & & \\
RMSE & $\mathbf{0 . 1 2}$ & 0.12 & 0.12 \\
MAE & $\mathbf{0 . 1 0}$ & 0.10 & 0.10 \\
MBE & $\mathbf{- 0 . 0 8}$ & - & - \\
& & 0.09 & 0.08
\end{tabular}

${ }^{a}$ Data for this comparison are based on the subsample of ABCD and AE33 data during times when the mobile lab was parked (speed $=0$ ) for at least 60 seconds within $80 \mathrm{~m}$ of site 3 or site 4. Median visit length: 7.25 minutes. $A B C D$ values are calculated as the average of $0.5 \mathrm{~Hz}$ measurements by all ABCD sensors at a site for the duration of the co-location. 


\section{S5. Supporting Information References}

(1) Caubel, J. J.; Cados, T. E.; Preble, C. V.; Kirchstetter, T. W. A Distributed Network of 100 Black Carbon Sensors for 100 Days of Air Quality Monitoring in West Oakland, California. Environ. Sci. Technol. 2019, 53 (13), 7564-7573. https://doi.org/10.1021/acs.est.9b00282.

(2) Padró-Martínez, L. T.; Patton, A. P.; Trull, J. B.; Zamore, W.; Brugge, D.; Durant, J. L. Mobile Monitoring of Particle Number Concentration and Other Traffic-Related Air Pollutants in a near-Highway Neighborhood over the Course of a Year. Atmos. Environ. 2012, 61, 253-264. https://doi.org/10.1016/j.atmosenv.2012.06.088.

(3) Patton, A. P.; Perkins, J.; Zamore, W.; Levy, J. I.; Brugge, D.; Durant, J. L. Spatial and Temporal Differences in Traffic-Related Air Pollution in Three Urban Neighborhoods near an Interstate Highway. Atmos. Environ. 2014, 99, 309-321. https://doi.org/10.1016/j.atmosenv.2014.09.072.

(4) Shah, R. U.; Robinson, E. S.; Gu, P.; Robinson, A.; Apte, J. S.; Presto, A. A. High Spatial Resolution Mapping of Aerosol Composition and Sources in Oakland, California Using Mobile Aerosol Mass Spectrometry. Atmospheric Chem. Phys. Discuss. 2018, 1-31. https://doi.org/10.5194/acp-2018-703.

(5) Li, H. Z.; Gu, P.; Ye, Q.; Zimmerman, N.; Robinson, E. S.; Subramanian, R.; Apte, J. S.; Robinson, A. L.; Presto, A. A. Spatially Dense Air Pollutant Sampling: Implications of Spatial Variability on the Representativeness of Stationary Air Pollutant Monitors. Atmospheric Environ. X 2019, 2, 100012. https://doi.org/10.1016/j.aeaoa.2019.100012.

(6) Miller, D. J.; Actkinson, B.; Padilla, L.; Griffin, R. J.; Moore, K.; Lewis, P. G. T.; GardnerFrolick, R.; Craft, E.; Portier, C. J.; Hamburg, S. P.; Alvarez, R. A. Characterizing Elevated Urban Air Pollutant Spatial Patterns with Mobile Monitoring in Houston, Texas. Environ. Sci. Technol. 2020. https://doi.org/10.1021/acs.est.9b05523.

(7) Brantley, H. L.; Hagler, G. S. W.; Kimbrough, E. S.; Williams, R. W.; Mukerjee, S.; Neas, L. M. Mobile Air Monitoring Data-Processing Strategies and Effects on Spatial Air Pollution Trends. Atmospheric Meas. Tech. 2014, 7 (7), 2169-2183. https://doi.org/10.5194/amt-72169-2014.

(8) Apte, J. S.; Kirchstetter, T. W.; Reich, A. H.; Deshpande, S. J.; Kaushik, G.; Chel, A.; Marshall, J. D.; Nazaroff, W. W. Concentrations of Fine, Ultrafine, and Black Carbon Particles in Auto-Rickshaws in New Delhi, India. Atmos. Environ. 2011, 45 (26), 4470 4480. https://doi.org/10.1016/J.ATMOSENV.2011.05.028.

(9) Van Poppel, M.; Peters, J.; Bleux, N. Methodology for Setup and Data Processing of Mobile Air Quality Measurements to Assess the Spatial Variability of Concentrations in Urban Environments. Environ. Pollut. 2013, 183, 224-233. https://doi.org/10.1016/j.envpol.2013.02.020.

(10) Peters, J.; Van den Bossche, J.; Reggente, M.; Van Poppel, M.; De Baets, B.; Theunis, J. Cyclist Exposure to UFP and BC on Urban Routes in Antwerp, Belgium. Atmos. Environ. 2014, 92, 31-43. https://doi.org/10.1016/j.atmosenv.2014.03.039.

(11) Van Den Bossche, J.; Peters, J.; Verwaeren, J.; Botteldooren, D.; Theunis, J.; De Baets, B. Mobile Monitoring for Mapping Spatial Variation in Urban Air Quality: Development and Validation of a Methodology Based on an Extensive Dataset. Atmos. Environ. 2015, 105, 148-161. https://doi.org/10.1016/j.atmosenv.2015.01.017.

(12) Kerckhoffs, J.; Hoek, G.; Messier, K. P.; Brunekreef, B.; Meliefste, K.; Klompmaker, J. O.; Vermeulen, R. Comparison of Ultrafine Particle and Black Carbon Concentration 
Predictions from a Mobile and Short-Term Stationary Land-Use Regression Model.

Environ. Sci. Technol. 2016, 50 (23), 12894-12902.

https://doi.org/10.1021/acs.est.6b03476.

(13) Levy, I.; Mihele, C.; Lu, G.; Narayan, J.; Hilker, N.; Brook, J. R. Elucidating Multipollutant Exposure across a Complex Metropolitan Area by Systematic Deployment of a Mobile Laboratory. Atmospheric Chem. Phys. 2014, 14 (14), 7173-7193.

https://doi.org/10.5194/acp-14-7173-2014.

(14) Apte, J. S.; Messier, K. P.; Gani, S.; Brauer, M.; Kirchstetter, T. W.; Lunden, M. M.; Marshall, J. D.; Portier, C. J.; Vermeulen, R. C. H.; Hamburg, S. P. High-Resolution Air Pollution Mapping with Google Street View Cars: Exploiting Big Data. Environ. Sci. Technol. 2017, 51 (12), 6999-7008. https://doi.org/10.1021/acs.est.7b00891. 